\title{
钠离子电池硬碳负极储钠机理及优化策略
}

\author{
董瑞琪吴锋白莹*吴川* \\ (北京理工大学材料学院 环境科学与工程北京市重点实验室 北京 100081)
}

\begin{abstract}
摘要 钠离子电池因具有成本低、安全性高等优势, 被认为是一种非常适合应用于大规模储能领域的电化学储能技术. 合适的负极材料是促进钠离子电池实现商业化的关键之一. 硬碳材料由于具有丰富的碳源、低成本、无毒环保，且储 钠电位低而被认为是最可能被实用化的钠离子电池负极材料. 然而硬碳负极的实际应用中也面临着首周库伦效率低、 长循环稳定性不足以及倍率性能较差等问题, 近年来众多研究者致力于硬碳负极的性能优化研究, 本综述从结构调 控、形貌设计、界面构造、电解液优化四方面总结了近年来钠离子电池硬碳负极的性能优化策略研究进展, 分析了每 种优化策略的优点和不足, 并进一步讨论了钠离子电池硬碳负极实用化进程中面临的瓶颈问题和挑战.
\end{abstract}

关键词 钠离子电池; 负极; 硬碳; 性能优化; 实用化

\section{Sodium Storage Mechanism and Optimization Strategies for Hard Carbon Anode of Sodium Ion Batteries}

\author{
Ruiqi Dong Feng Wu Ying Bai* Chuan Wu* \\ (Beijing Key Laboratory of Environmental Science and Engineering, School of Materials Science and Engineering, \\ Beijing Institute of Technology, Beijing 100081, China)
}

\begin{abstract}
Sodium ion batteries (SIBs) have been regarded as a very suitable electrochemical energy storage technology for large-scale energy storage due to its low cost and high safety. Suitable anode material is one of the keys to boosting the commercialization process of SIBs. Significantly, hard carbon (HC) anode is considered as the most practical anode material for SIBs due to its rich natural sources, low cost, non-toxic, environmentally friendly, and low sodium storage voltage. However, hard carbon anode also faces the problems of low initial Columbic efficiency, insufficient long cycle stability and poor rate performance, which restrict its practical application in SIBs. In recent years, extensive investigations have been done to improve the performance of hard carbon anode, herein, this review discusses the recent progress of performance optimization strategies of hard carbon anode from four aspects, including structure control, morphology design, interface manufacture, and electrolyte optimization and conducts an analysis of the merits and demerits of each optimization method. Moreover, this review also discusses the bottlenecks and challenges in the process of practical application of hard carbon anode for sodium ion batteries.
\end{abstract}

Keywords sodium ion battery; anode; hard carbon; performance optimization; practical application

\section{1 引言}

近年来, 化石能源消费的碳排放导致环境问题日益 突出, 规模开发可再生能源如太阳能、风能、潮汐能等, 推进能源消费结构向低碳化和清洁化方向转型已成为 全球重要共识. 但可再生能源的不稳定性制约了其大规 模应用, 并由此导致了弃风、弃光问题. 大规模储能技 术是实现可再生能源大规模发电、并入电网的必要条 件 ${ }^{[1]}$. 锂离子电池是当前储能领域的研究热门之一. 自 20 世纪 90 年代被 SONY 实现商业化以来, 锂离子电池 便被广泛应用于可移动电子设备以及电动汽车等领域. 随着锂离子电池的越来越广泛的应用, 地壳中储量并不 丰富的锂资源将无法满足日益增长的巨大需求, 因此开
发能够在储能领域有效替代锂离子电池的其他电池技 术迫在眉眓 ${ }^{[2]}$.

与锂相比，地壳中钠资源非常丰富 $(2.75 \%$ vs. $0.0065 \%)$, 且分布较为均匀, 同时钠与锂是同主族元素, 具有相似的化学性质, 所以钠离子电池的开发可以借鉴 锂离子电池的成功经验 ${ }^{[3]}$. 近年来, 研究者们对钠离子 电池进行了大量研究, 开发了多种正负极材料和电解液 体系 ${ }^{[4]}$. 正极方面借鉴锂离子电池正极材料的研究经验, 研究者们开发了层状或隧道结构的过渡金属氧化物、普 鲁士蓝类正极材料以及聚阴离子型正极材料等 ${ }^{[5-12]}$. 电 解液方面, 将锂离子电池研究的电解液中的锂盐替换成 相应的钠盐, 形成了以高氯酸钠 $\left(\mathrm{NaClO}_{4}\right)$ 、六氟磷酸钠 $\left(\mathrm{NaPF}_{6}\right)$ 、双三氟甲基磺酰亚胺钠 $(\mathrm{NaTFSI})$ 、二双氟磺酰

\footnotetext{
* E-mail: membrane@bit.edu.cn (Y. Bai); chuanwu@bit.edu.cn (C. Wu)

Received June 22, 2021; published August 19, 2021.

Project supported by the National Natural Science Foundation of China (No. 21975026).

项目受国家自然科学基金(No. 21975026)资助.
} 
亚胺钠 $(\mathrm{NaFSI}) 、$ 三氟甲磺酸钠 $(\mathrm{NaOTf})$ 中的某种盐为溶 质, 碳酸乙烯酯 $(\mathrm{EC})$ 、碳酸丙烯酯 $(\mathrm{PC})$ 、碳酸二甲酯 $(\mathrm{DMC})$ 、碳酸二乙酯(DEC)、碳酸甲乙酯 $(\mathrm{EMC}) 、 乙 二$ 醇二甲醚(DME)、二乙二醇二甲醚(DEGDME)、四乙二 醇二甲醚(TEGDME)等溶剂中的一种或几种混合为溶 剂的多种电解液体系 ${ }^{[13-15]}$. 近年来, 为了提高电池安全 性和电化学性能, 研究者们也开发出了固态电解质以及 一些其他新型电解液体系 ${ }^{[16-22]}$. 负极研究方面, 锂离子 电池商用化的石墨负极由于成本低、稳定性好而被首先 考虑应用到钠离子电池体系, 然而, 在传统的酯基电解 液中, 钠离子无法嵌入石墨层间与石墨形成热力学稳定 的 Na-C 化合物, 用作钠离子电池负极时只有 35 $\mathrm{mAh} \cdot \mathrm{g}^{-1}$ 左右的吸附比容量 ${ }^{[23]}$, 即使后来研究发现醚基 电解液中石墨可以存储溶剂化钠离子, 比容量也只有 $150 \mathrm{mAh} \cdot \mathrm{g}^{-1}$ 左右 ${ }^{[24-27]}$, 这非常不利于开发高能量密度 的钠离子全电池. 因此, 缺乏合适的负极材料制约了钠 离子电池的进一步发展, 直到 2000 年, Dahn 等 ${ }^{[28]}$ 用葡 萄糖碳化制备的硬碳负极比容量高达 $300 \mathrm{mAh} \cdot \mathrm{g}^{-1}$, 接 近石墨储锂的比容量, 尽管其首周库伦效率 (initial Coulomb efficiency, ICE)和循环稳定性无法满足实用化 要求, 但其研究掀起了钠离子电池负极材料的研究热 潮. 在接下来的 20 年中, 大量的负极材料被广泛研究, 包括金属/合金 $(\mathrm{Sb} 、 \mathrm{Sn} 、 \mathrm{P} \text { 及其合金等 })^{[29-31]}$, 金属氧/硫 /磷/硒化物 $\left(\mathrm{SnO}_{2} 、 \mathrm{Fe}_{3} \mathrm{O}_{4} 、 \mathrm{TiO}_{2} 、 \mathrm{MoS}_{2} 、 \mathrm{SnS}_{2} 、 \mathrm{NiS}_{2}\right.$ 、 $\mathrm{VS}_{2} 、 \mathrm{NiP}_{3} 、 \mathrm{Sn}_{4} \mathrm{P}_{3} 、 \mathrm{FeP}_{4} 、 \mathrm{CoSe} 、 \mathrm{ZnSe} 、 \mathrm{NiSe}_{2}$ 等 $)^{[32-45]}$, 碳材料(膨胀石墨、石墨烯、软碳、硬碳等) $)^{[46-51]}$. 其中, 硬 碳材料由于既可以通过裂解生物质碳源制备也可以通 过裂解高分子聚合物获得，具有来源广泛、无毒环保、 储钠电位低和比容量较高等优势而被广泛研究.

硬碳材料通常被认为是难石墨化的碳材料的统称, 其微观结构是由弯曲的类石墨片堆叠的短程有序微区, 各微区随机无序堆叠留下较多纳米孔洞. 由于其往往具 有较大的层间距(通常大于 $0.37 \mathrm{~nm}$ ), 较多的纳米孔洞, 以及较多的缺陷位点, 因而可以储存较多的钠离子, 具 有较高的比容量. 然而其实际应用却受到首周库伦效率 低、倍率性能较差和循环稳定性不足等的制约, 为了促 进其走向实用化, 研究者们致力于其性能优化策略的研 究. 近年来, 研究者们尝试了大量的优化手段, 根据其 优化方式不同可以大致分为结构调控、形貌设计、界面 构造、电解液优化等方面. 本文梳理了近年来的优化研 究结果, 并对每种优化手段的优缺点进行了分析, 同时 对钠离子电池硬碳负极商业化进程面临的瓶颈问题和 挑战进行了讨论.

\section{2 硬碳的结构和储钠机理}

\section{1 硬碳的结构}

硬碳也被称为 “非石墨化碳” , 由扭曲的石墨烯片 堆叠而成, 即使在高于 $3000{ }^{\circ} \mathrm{C}$ 的温度下, 这些扭曲的
石墨烯片也无法完全展开或压平而进一步堆积成石 墨 ${ }^{[52]}$. Dahn 等 ${ }^{[28]}$ 提出的 “纸牌屋” 模型是第一个也是最 广泛被接受的硬碳结构模型. 该模型表明硬碳结构中存 在小的弯曲的石墨烯片平行堆叠的短程有序微区，堆积 层数一般限制在 $2 \sim 6$ 层，横向尺寸限制在 $\approx 4 \mathrm{~nm}$, 长程 无序排列, 不同取向的微区之间形成了丰富的纳米孔. 硬碳的(002)层间距通常在 $0.37 \sim 0.40 \mathrm{~nm}$ 之间, 远比石 墨的 $0.335 \mathrm{~nm}$ 大. 通过杂原子掺杂和调控碳化工艺可以 进一步增大层间距从而增加储钠容量. 纳米孔是硬碳结 构中另一重要的组成部分, 通常纳米孔是开放的或封闭 的. 开放的孔往往导致了较大的比表面积, 带来了过多 的固体电解质界面(solid electrolyte interphase, SEI)膜的 形成, 从而导致了较低的 $\mathrm{ICE}^{[53]}$. 闭孔可提供储钠的活 性位点, 但闭孔中也可能形成 SEI 膜而降低 $\mathrm{ICE}^{[54]}$. 硬 碳的比表面积、孔隙体积和孔径分布一般由气体吸脱附 测试来表征, 由于确定封闭孔隙的大小和数量具有挑战 性, 所以试图将闭孔孔隙结构与硬碳的性能联系起来是 存在挑战的. 除了短程有序微区和纳米孔外, 还存在着 空位、边缘和缺陷位点. 虽然硬碳中的大部分碳原子以 六元碳环的形式存在, 但也有一些五边形或七边形缺陷 位点. 通常, 缺陷数量随热解温度的升高而减少, 随比 表面积的增加而增加. 前驱物的性质对缺陷数量也有非 常大的影响，中分子量前驱体通常比高分子量前驱体制 备的硬碳具有更多的缺陷 ${ }^{[55]}$. 此外, 杂原子掺杂往往也 会引入较多缺陷位点.

\section{2 硬碳的储钠机理}

研究钠离子的储存机理, 阐明硬碳的结构与电化学 性能之间的关系对指导硬碳结构优化提升储钠性能具 有重要意义. 然而由于硬碳无定型结构的特征, 使得建 立硬碳结构和储钠性能之间的关系比较困难. 研究者们 近年来也提出了 $\mathrm{Na}^{+}$在硬碳中的不同存储机制. 最早的 机制主要是 “插层-吸附” 机制(图 1a)和 “吸附-插层” 机制(图 1b) ${ }^{[56]}$. Komaba 等 ${ }^{[57]}$ 通过原位 X 射线衍射(X-ray diffraction, XRD) 分析发现, 当阳极从 $2.0 \mathrm{~V}$ 放电到 $0.1 \mathrm{~V}$ 时, 硬碳的(002)峰向较小的角度移动, 当充电到 $2.0 \mathrm{~V}$ 时, 硬碳的(002)峰恢复. 因而提出斜坡区 $(2.0 \sim 0.1 \mathrm{~V})$ 对 应 $\mathrm{Na}^{+}$可逆地 “插入” 到(002)层间. Cao 等 ${ }^{[56]}$ 基于原位 $\mathrm{XRD}$ 和非原位拉曼分析表明, 斜坡容量的占比与 $I_{\mathrm{D}} /\left(I_{\mathrm{D}}\right.$ $\left.+I_{\mathrm{G}}\right)$ 的比率相关, 这说明斜坡容量取决于缺陷的数量, 原位 XRD 表明层间变化发生在平台区, 所以是 “吸附插层”机制. 此外, 减小硬碳颗粒尺寸或引入杂原子, 都 会导致更多的缺陷，并产生更多的吸附容量，这也证实 了斜坡区容量和缺陷数量之间的关系 ${ }^{[58-59]}$. Xu 等 ${ }^{[60]}$ 通 过 XRD 和充放电曲线细分研究发现微观结构可分成三 类: (1) $<0.36 \mathrm{~nm}$ 的类石墨区，不具有储钠能力; (2) $0.36 \sim 0.4 \mathrm{~nm}$ 层间区域可提供嵌入型储钠; (3) $>0.4 \mathrm{~nm}$ 的层间是以赝电容吸附的形式贡献储钠容量(图 1c). 该 研究提出理论平台容量对应于 $\mathrm{NaC}_{8}$ 化合物形成. 另一 
种比较典型的储钠机制是 “吸附-微孔填充” 机制. 早期 研究基于小角 X 射线散射(small-angle X-ray scattering, $\mathrm{SAXS}$ )分析发现, 当放电电压从 $0.20 \mathrm{~V}$ 到 $0.00 \mathrm{~V}$ 时, $q \approx$ $0.3 \sim 0.7 \mathrm{~nm}^{-1}$ (对应于纳米孔尺寸 $\approx 1.4 \mathrm{~nm}$ ) 的强度呈可 逆下降, 表明平台区有纳米孔被可逆填充 ${ }^{[57]}$. 此后也有
研究将平台容量归因于 “微孔填充”，因为当硬碳的孔 隙被硫填充时，低压平台消失，直观地证明了平台区来 自 $\mathrm{Na}^{+}$在微孔的填充 ${ }^{[61]}$. 此外, Tarascon 等 ${ }^{[62]}$ 研究发现, 在碳化温度高达 $2000{ }^{\circ} \mathrm{C}$ 时, 硬碳中存在大量的微孔, 放电至 $0.1 \mathrm{~V}$ 时产生一个占主导地位的电压平台，斜坡
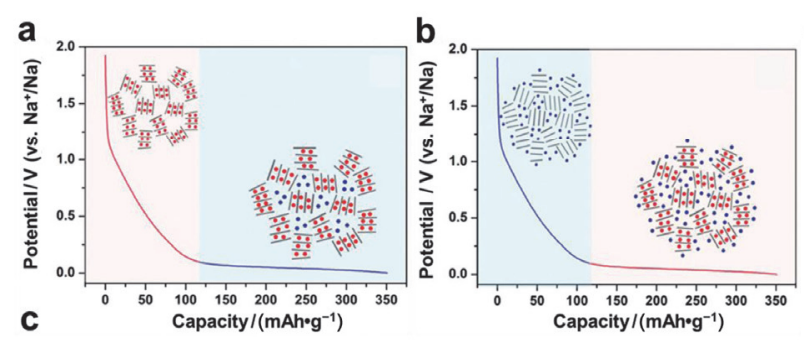

- Pseudo-adsorption Defect-adsorption - Interlayer-insertion $\square \quad$ Electrolyte
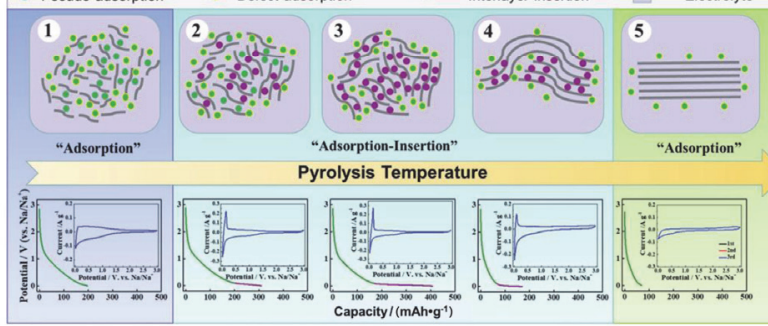

e f (1) Na adsorption (2) Na intercalation

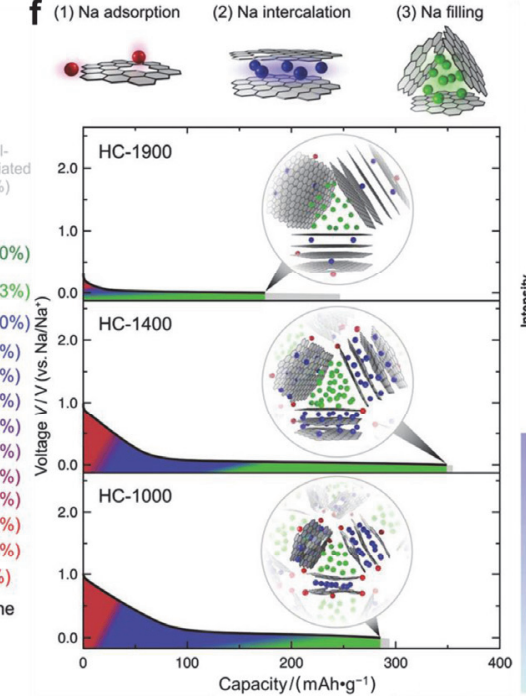

Pore-forming + Pore-closing Strategy
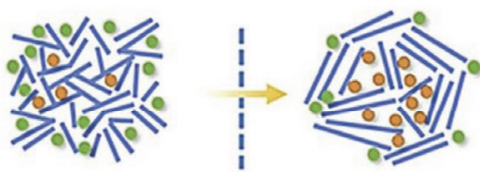

- $\mathrm{Na}^{+}$storage sites at slope region

- $\mathrm{Na}^{+}$storage sites at plateau region
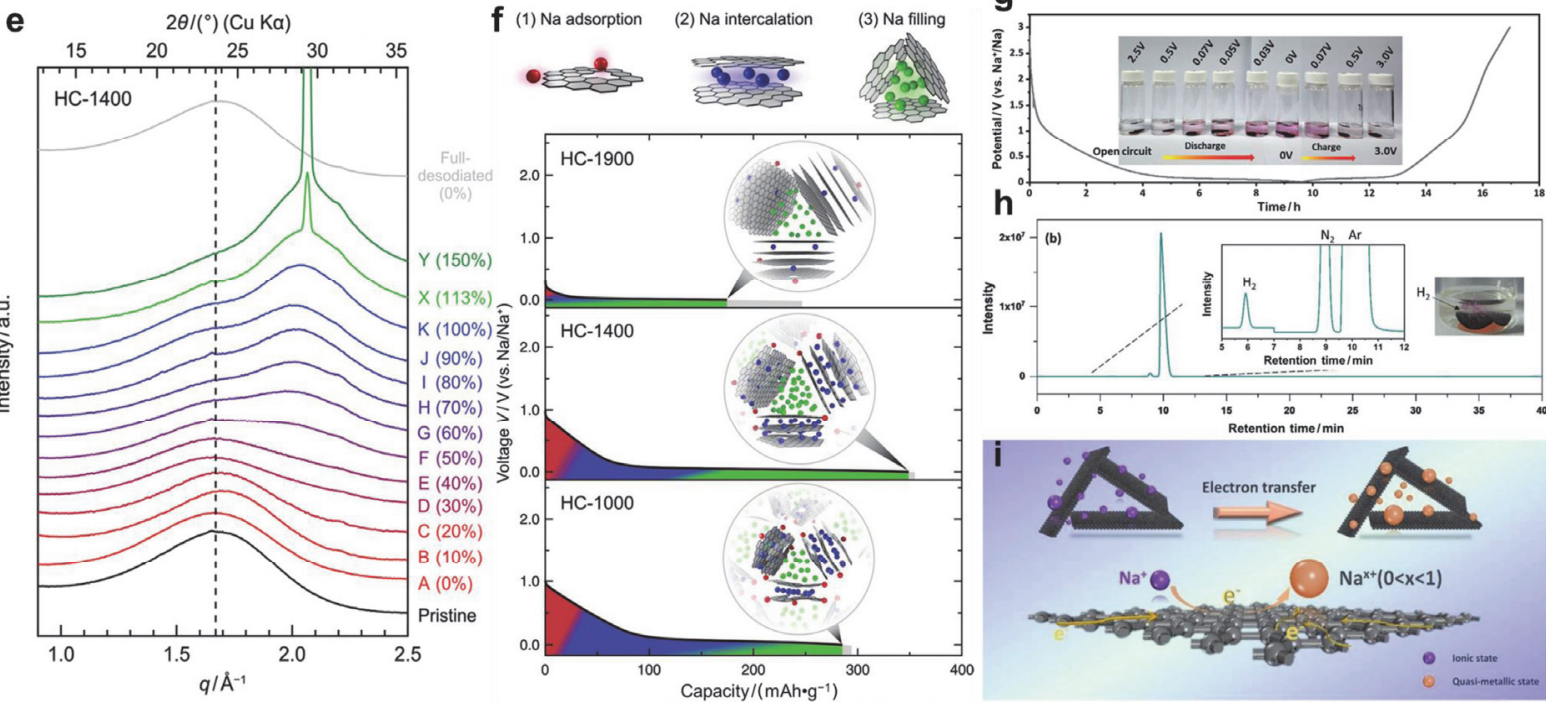

图 1 钠离子在硬碳中储存机理示意图: (a) “插层-吸附” 机制, (b) “吸附-插层” 机制[56]. 已获得参考文献[56]的转载许可, 版权所有(C) 2017 WILEY-VCH Verlag GmbH \& Co. KGaA, Weinheim. (c) 硬碳的微观结构随热解温度的变化的演变及对应的储钠机制和行为示意图 ${ }^{[60]}$. 已获得参 考文献[60]的转载许可, 版权所有( 2019 WILEY-VCH Verlag GmbH \& Co. KGaA, Weinheim. (d) 多孔碳孔结构调整和闭孔储钠机制示意图[63]. 已 获得参考文献[63]的转载许可, 版权所有 ( 2019 WILEY-VCH Verlag GmbH \& Co. KGaA, Weinheim. (e) 不同的钠化阶段的硬碳电极的非原位 WAXS 曲线, (f) 硬碳储钠的 “吸附一插层一孔充填” 机理示意图, 灰色区域表示由于反应缓慢而未使用的容量 ${ }^{[67]}$. 已获得参考文献[67]的转载许 可, 版权所有 $(2019$ WILEY-VCH Verlag GmbH \& Co. KGaA, Weinheim. (g)放电/充电到不同电压的硬碳电极与质子溶剂的化学反应, (h) 完全钠 化的电极与乙醇反应后产生的 $\mathrm{H}_{2}$ 的气相色谱图, (i) 硬碳中钠的稳态示意图: 在钠离子插入硬碳电极过程中伴随它们之间部分的电子转移形成准 金属钠 ${ }^{[68]}$. 已获得参考文献[68]的转载许可, 版权所有 $\odot 2021$ Wiley-VCH GmbH

Figure 1 Schematic illustration of the mechanisms for Na-ion storage in hard carbon: (a) "intercalation-adsorption" mechanism, (b) "adsorption-intercalation" mechanism ${ }^{[56]}$. Reprinted with permission from ref. [56]. Copyright $\mathbb{C} 2017$ WILEY-VCH Verlag GmbH \& Co. KGaA, Weinheim. (c) Schematic illustration of the evolution of the microstructure, sodium storage mechanism and behavior with the pyrolysis temperature of HC ${ }^{[60]}$. Reprinted with permission from ref. [60]. Copyright $(\mathcal{O} 2019$ WILEY-VCH Verlag GmbH \& Co. KGaA, Weinheim. (d) Schematic illustration of tuning pore structure of porous carbon and sodium storage mechanism of closed pores ${ }^{[63]}$. Reprinted with permission from ref. [63]. Copyright $(2019$ WILEY-VCH Verlag $\mathrm{GmbH} \& \mathrm{Co} . \mathrm{KGaA}$, Weinheim. (e) Ex-situ WAXS profiles of hard carbon electrodes at various stage of sodiation, (f) schematic diagrams of the sodium storage mechanism of "adsorption-intercalation-pore filling" in hard carbon. Gray areas indicate unused capacity because of slow kinetics ${ }^{[67]}$. Reprinted with permission from ref. [67]. Copyright (C) 2019 WILEY-VCH Verlag GmbH \& Co. KGaA, Weinheim. (g) Chemical reaction of protic solvents with the $\mathrm{HC}$ electrode after discharged/charged to different voltages, (h) gas-chromatography chromatogram of gases with $\mathrm{H}_{2}$ after ethanol reaction with fully sodiated electrodes, (i) schematic illustration of the steady states of sodium in hard carbon: the insertion of $\mathrm{Na}^{+}$into $\mathrm{HC}$ electrode accompanies by partial electron transfer between them with the formation of quasi-metallic sodium ${ }^{[68]}$. Reprinted with permission from ref. [68]. Copyright $\subset$ C $2021 \mathrm{Wiley-VCH}$ $\mathrm{GmbH}$ 
容量可以忽略, 表明硬碳中的微孔数量与电压平台有相 关性. 近期 $\mathrm{Hu}$ 等 ${ }^{[63-64]}$ 利用压录法、 $\mathrm{N}_{2}$ 吸附、 SAXS 和 骨密度法, 结合储钠性能对硬碳孔的类型和作用进行了 分析, 明确了各种孔的作用: 开放的大孔有助于循环过 程中稳定碳结构, 开放的微孔影响 ICE, 封闭的纳米孔 有利于平台容量的增加. 基于此提出平台容量是纳米闭 孔提供的机制(图 1d). 此外, 也有研究利用恒电流间歇 滴定技术 (galvanostatic intermittent titration technique, GITT)曲线分析 $\mathrm{Na}^{+}$扩散系数变化趋势来研究储钠机制, 硬碳阳极的 GITT 曲线一般显示出三个区域, 所以可以 合理地推断, GITT 曲线上的三个区域来自硬碳负极中 $\mathrm{Na}^{+}$存储的三个不同阶段. 在 $0.1 \mathrm{~V}$ 以上的斜坡区, 扩散 系数高, 这可能来自缺陷等易于捕获 $\mathrm{Na}^{+}$的位置储钠, 在 $0.1 \sim 0.03 \mathrm{~V}$ 的条件下, 扩散系数显著降低, 这可能来 自于 $\mathrm{Na}^{+}$在硬碳微区的层间嵌入. 在约 $0.03 \sim 0 \mathrm{~V}$ 区间, 扩散系数突然呈现上升趋势, 这可能是由于孔隙中填充 了准金属性的 $\mathrm{Na}$ 团簇 ${ }^{[65-66]}$. 对于硬碳储钠是否存在金 属态的钠一直以来也备受关注. Titirici 等 ${ }^{[66]}$ 通过对 ${ }^{23} \mathrm{Na}$ 固态核磁共振分析表明，随着 $\mathrm{Na}$ 的金属化程度的增加， $\mathrm{Na}$ 的费米能级的态密度也随之增加, 这说明随着孔隙 尺寸的增加, 孔隙中 $\mathrm{Na}$ 的金属性更强. 最近, Yamada 等 ${ }^{[67]}$ 对不同温度下合成的硬碳样品进行了原位广角 $\mathrm{X}$ 射线散射(wide-angle X-ray scattering, WAXS)分析, 发 现当硬碳样品的钠化程度超过 $50 \% \sim 60 \%$ 时, 在 $q \approx$ $20 \sim 21 \mathrm{~nm}^{-1}$ 处出现了一个宽峰, 并且随着钠化程度的 增加而增大(图 1e). 当暴露于微量的 $\mathrm{H}_{2} \mathrm{O} 、 \mathrm{O}_{2}$ 或 $\mathrm{CO}_{2}$ 时, 宽峰消失, 表现出金属 $\mathrm{Na}$ 的典型特征. 与块状 $\mathrm{Na}$ 金属 的尖峰不同, 该宽峰可能是由硬碳纳米孔沉积的准金属 $\mathrm{Na}$ 团簇引起的, 因此, “吸附一插层一孔充填” 储钠机 制可以更好地解释大部分实验结果, 更具有说服力 (图 1f). 然而准金属 $\mathrm{Na}$ 的存在仍然需要更多的证据. 最近, Bai 和 $\mathrm{Wu}$ 等 ${ }^{[68]}$ 发现将不同储钠态的极片与含酚酞的乙 醇溶液反应均可发生显色现象且伴随着气泡产生(图 $1 \mathrm{~g}$ ), 气相色谱确定了气体成分是氢气(图 $1 \mathrm{~h}$ ), 对反应后 的乙醇溶液中 $\mathrm{Na}^{+}$的浓度以及离子电导率进行检测显示 随着极片放电程度的增加, 反应后的乙醇溶液中 $\mathrm{Na}^{+}$的 浓度以及离子电导率也逐渐提高, 而随着极片充电程度 的增加, 反应后的乙醇溶液中 $\mathrm{Na}^{+}$的浓度以及离子电导 率逐渐降低. 基于这些研究结果, 钠离子以 “准金属” 的形态稳定存储在硬碳材料内部而非正一价的 $\mathrm{Na}^{+}$形式 的机理被首次提出(图 1i).

\section{3 钠离子电池硬碳负极的性能优化}

\section{1 结构调控}

硬碳的微观结构是由弯曲的类石墨片堆叠形成短 程有序的微区, 同时各微区随机无序堆叠留下较多纳米 孔洞, $\mathrm{Na}^{+}$可以通过缺陷吸附, 层间嵌入, 以及纳米孔填
充等方式储存到硬碳中，因此硬碳的微观结构将直接影 响储钠能力. 调控硬碳微观结构的主要思路有两种, 一 是调控碳化过程, 包括碳化温度、变温速率、碳化方式 等. 通常认为碳化温度升高, 变温速率减慢, 可以给碳 层重排提供足够的能量和时间，有利于增加硬碳结构的 有序性，减少孔隙和缺陷，这有利于提升首周库伦效率 和循环稳定性 ${ }^{[69-74]}$. 例如, Cao 等 ${ }^{[69]}$ 以蔗糖水热制备的 碳球为前驱体, 采用 $0.5{ }^{\circ} \mathrm{C} / \mathrm{min}$ 的变温速率和 $1300{ }^{\circ} \mathrm{C}$ 这一较高的碳化温度制备了低缺陷低孔隙率的硬碳负 极(HC-0.5), 获得了 $361 \mathrm{mAh} \cdot \mathrm{g}^{-1}$ 的高比容量和 $86.1 \%$ 的 高首周库伦效率，以及循环 100 周后 $93.4 \%$ 的高容量保 持率，结合基于密度泛函理论(density functional theory, DFT)的第一性原理计算研究发现碳层中的缺陷可以困 住 $\mathrm{Na}^{+}$并对后来的钠离子形成排斥电场, 降低 $\mathrm{Na}^{+}$的层 间嵌入容量并直接影响首周库伦效率(图 2), 因此, 低缺 陷的硬碳负极往往能够获得高的首周库伦效率. 又如, Kim 等 ${ }^{[70]}$ 采用慢速低温热解后高温碳化两步碳化法制 备硬碳，发现低温热解过程部分石墨化后有助于高温碳 化过程中石墨化区域的进一步形成和长大，从而得到石 墨化程度较高的硬碳, 获得了 $71 \%$ 的首周库伦效率和 $194 \mathrm{mAh} \cdot \mathrm{g}^{-1}$ 的 $0.1 \mathrm{~V}$ 下的平台容量.

另外，通过引入一种或多种杂原子 $(\mathrm{N} 、 \mathrm{O} 、 \mathrm{P} 、 \mathrm{~S} 、$ $\mathrm{Li} 、 \mathrm{Na} 、 \mathrm{~K} 、 \mathrm{Ca}$ 等)也会引起微观结构的改变. 通常引入 阴离子 $(\mathrm{N} 、 \mathrm{~F} 、 \mathrm{P} 、 \mathrm{~S}$ 等)可以有效的改变材料的层间距、 表面润湿性、电子导电性，从而改善其储钠性能. 其中 $\mathrm{N}$ 掺杂由于可以引入缺陷，提升电子电导从而提升比容 量和倍率性能而被广泛研究. Huang 等 ${ }^{[75]}$ 在 2013 年最先 以吡咯单体同时为碳源和氮源制备了 $\mathrm{N}$ 掺杂碳纤维，在 $20 \mathrm{~A} \cdot \mathrm{g}^{-1}$ 电流密度下展现出 $73 \mathrm{mAh} \cdot \mathrm{g}^{-1}$ 高比容量, 然而 其首周库伦效率仅有 $41.8 \%$. 此后，大量 $\mathrm{N}$ 掺杂的硬碳 负极通过直接裂解含氮的前驱体 ${ }^{[76]}$ 、在 $\mathrm{Ar} / \mathrm{NH}_{3}$ 混合气 氛中碳化 ${ }^{[77]}$ 、或通过等离子处理 ${ }^{[78]}$ 、化学气相沉积 ${ }^{[79]}$ 等复杂的方法被合成，包括 $\mathrm{N}$ 掺杂碳纳米片 ${ }^{[80-81] 、} \mathrm{~N}$ 掺 杂碳纳米纤维 ${ }^{[82-86] 、 N}$ 掺杂碳球 ${ }^{[87-89]}$ 等. 同时, 天然含 氮的生物质硬碳也被广泛研究, Qian 和 Yan 等 ${ }^{[90]}$ 利用生 物质副产品豆渣制备了天然高 $\mathrm{N}$ 掺杂量(原子百分比 $9.89 \%)$ 的硬碳负极, 与 $\mathrm{Na}_{3} \mathrm{~V}_{2}\left(\mathrm{PO}_{4}\right)_{3}$ 组装钠离子全电池 能量密度高达 $146.1 \mathrm{Wh} \cdot \mathrm{kg}^{-1}$. Guo 等[91]制备了几丁质衍 生的 $\mathrm{N}$ 掺杂非晶碳纳米纤维, 并和普鲁士蓝正极组装钠 离子全电池, 实现了 $120 \mathrm{mAh} \cdot \mathrm{g}^{-1}$ 的高可逆比容量以及 200 次循环后 $90 \%$ 以上的容量保持率. 这些研究工作为 设计使用天然含杂原子的生物材料制备低成本硬碳负 极材料提供了思路. $\mathrm{P}$ 和 $\mathrm{S}$ 由于具有较大的原子半径, 往 往会引起硬碳结构产生较大的畸变, 从而引起层间距增 大和无序度增加. 层间距的增加不仅可以储存更多的 $\mathrm{Na}^{+}$，同时也提升了 $\mathrm{Na}^{+}$的快速扩散动力学; 另外, $\mathrm{S}$ 具 有电化学反应活性, 可以与 $\mathrm{Na}$ 发生可逆的电化学反应 贡献额外的容量 ${ }^{[92-102]}$. Wang 等 ${ }^{[93]}$ 通过热解 1,4,5,8-䒺四 

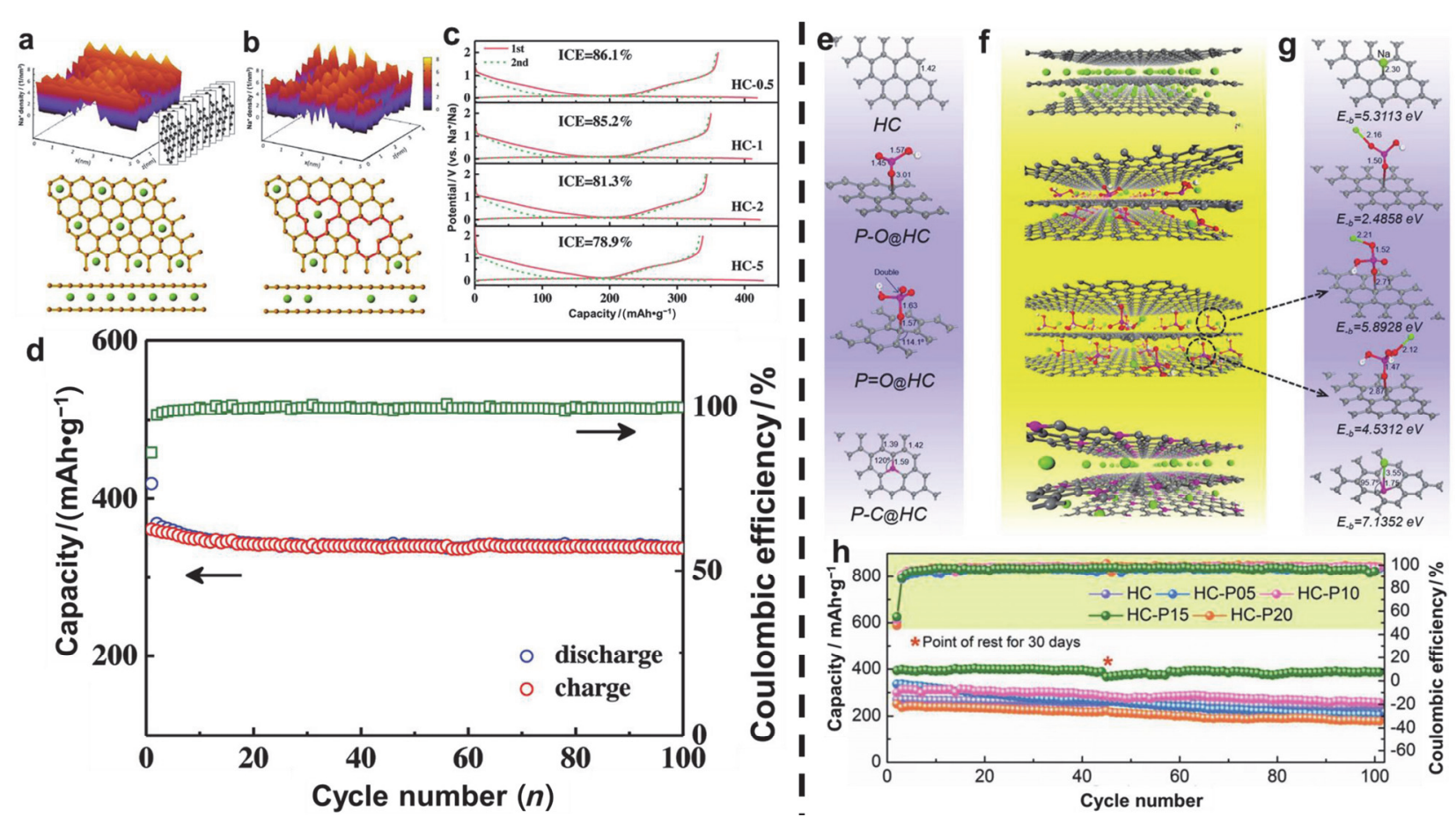

图 2 恒电位条件下石墨电极中 $\mathrm{Na}^{+}$的稳态分布(上图)及 $\mathrm{Na}^{+}$在石墨中存储的示意图(下图): (a) $\mathrm{Na}^{+}$在无空位缺陷电极中的分布, (b) $\mathrm{Na}^{+}$在存在空 位缺陷电极中的分布, (c) 电流密度 $20 \mathrm{~mA} \cdot \mathrm{g}^{-1}$ 条件下不同电极的首周充放电曲线和 (d) HC-0.5 电极的循环性能 ${ }^{[69]}$. 已获得参考文献[69]的转载许 可, 版权所有(C) 2018 WILEY-VCH Verlag GmbH \& Co. KGaA, Weinheim. (e) 磷功能化前后其中 P $=\mathrm{O}, \mathrm{P}-\mathrm{O}$ 和 $\mathrm{P}-\mathrm{C}$ 键形成的石墨层结构模型, (f, g) 钠离子吸附模型以及相应结合能, (h) 电流密度 $20 \mathrm{~mA} \cdot \mathrm{g}^{-1}$ 条件下不同电极的循环性能 ${ }^{[100]}$. 已获得参考文献[100]的转载许可, 版权所有 $(0) 2018$ WILEY-VCH Verlag GmbH \& Co. KGaA, Weinheim

Figure 2 Steady state $\mathrm{Na}^{+}$ion distribution in graphitic electrode under constant potential conditions (top) and schematic representation of $\mathrm{Na}^{+}$ion storage between the graphite layers (bottom). (a) $\mathrm{Na}^{+}$ion distribution in a vacancy defect free electrode, (b) $\mathrm{Na}^{+}$distribution in the presence of vacancy defects in the graphitic layers, (c) the first discharge-charge profiles for different electrodes at a current rate of $20 \mathrm{~mA} \cdot \mathrm{g}^{-1}$, (d) cycling performance for HC-0.5 electrode ${ }^{[69]}$. Reprinted with permission from ref. [69]. Copyright ( ${ }^{\circ} 2018$ WILEY-VCH Verlag GmbH \& Co. KGaA, Weinheim. (e) The structure models of graphite layers before and after phosphorous-functionalized including $\mathrm{P}=\mathrm{O}, \mathrm{P}-\mathrm{O}, \mathrm{P}-\mathrm{C},(\mathrm{f}, \mathrm{g})$ the Na-adsorption models and corresponding energies, (h) cycling performance for different electrodes at a current rate of $20 \mathrm{~mA} \bullet \mathrm{g}^{-1}{ }^{[100]}$. Reprinted with permission from ref. [100]. Copyright $\mathbb{C} 2018$ WILEY-VCH Verlag GmbH \& Co. KGaA, Weinheim

甲酸䣶(NTCDA)和 S 粉混合物制备了硫掺杂无定型碳, 得益于其超高的硫掺杂量(质量分数 $26.9 \%$ ), 和增大的 层间距, 得到了超高的倍率性能和优异的循环稳定性, 1 $\mathrm{A} \cdot \mathrm{g}^{-1}$ 电流密度下循环 1000 周后比容量高达 271 $\mathrm{mAh} \cdot \mathrm{g}^{-1}$. 同年 Huang 等 ${ }^{[94]}$ 合成了 $\mathrm{S}$ 质量分数 $15.17 \%$, 层间距增大到 $0.386 \mathrm{~nm}$ 的硬碳负极, 得到了 $73.6 \%$ 的首 周库伦效率和 $0.5 \mathrm{~A} \cdot \mathrm{g}^{-1}$ 电流密度下循环 700 周后比容 量高达 $303.2 \mathrm{mAh} \cdot \mathrm{g}^{-1}$ 的优异性能. 虽然硫掺杂可以贡 献部分储钠容量, 但其和钠反应的电位较高, 不利于制 备高能量密度的全电池. $\mathrm{Ji}$ 等 ${ }^{[95]}$ 以磷酸为磷源, 蔗糖为 碳源，通过液相混合制备前驱体后高温热解最先合成了 $\mathrm{P}$ 掺杂硬碳负极, 将比容量从 $283 \mathrm{mAh} \cdot \mathrm{g}^{-1}$ 提升到 359 $\mathrm{mAh} \cdot \mathrm{g}^{-1}$, 并通过研究证明了增加的容量来源于增大的 层间距, 掺杂的 $\mathrm{P}$ 不发生氧化还原反应. 之后, $\mathrm{Ji}$ 等 ${ }^{[98]}$ 同时制备了 $\mathrm{P}$ 掺杂和 $\mathrm{S}$ 掺杂的硬碳, 研究了其提升容量 的原因, 证明了 $\mathrm{P}$ 掺杂既能引起层间距增大, 又能引入 缺陷位点, 同时增加了嵌入容量和吸附容量; $\mathrm{S}$ 掺杂量 极少时主要是由于增大了层间距从而贡献了更多的嵌 入容量. 此后, Bai 和 $\mathrm{Wu}$ 等 ${ }^{[100]}$ 在配置纺丝液过程中将 碳源聚乙烯吡咯烷酩(PVP) 和磷源 $\mathrm{H}_{3} \mathrm{PO}_{4}$ 均匀混合, 通
过静电纺丝合成前驱体后高温碳化制备了 $\mathrm{P}$ 掺杂硬碳, 比容量高达 $393.4 \mathrm{mAh} \cdot \mathrm{g}^{-1}$, 并利用 DFT 计算证明增加 的容量主要由于 $\mathrm{P}=\mathrm{O}$ 和 $\mathrm{P}-\mathrm{C}$ 键加强了硬碳与 $\mathrm{Na}^{+}$的 结合能, 从而增加了吸附容量(图 2).

除了单阴离子掺杂外, 研究者们发现两种或多种杂 原子掺杂往往可以产生协同效应, 有助于性能的进一步 优化. Passerini 等 ${ }^{[103]}$ 利用生物废弃物苹果皮制备了天然 $\mathrm{N} / \mathrm{S}$ 共掺杂硬碳负极, 获得了 0.02 和 $1 \mathrm{~A} \cdot \mathrm{g}^{-1}$ 电流密度下 比容量分别为 245 和 $112 \mathrm{mAh} \cdot \mathrm{g}^{-1}$ 的电化学性能. Song 等 ${ }^{[104]}$ 利用根瘤菌中富含 $\mathrm{N}$ 和 $\mathrm{P}$ 元素的优势, 将豆根进 行碳化制备了天然 N/P 共掺杂的硬碳, 表现出了优异的 储钠性能 $\left(2 \mathrm{~A} \cdot \mathrm{g}^{-1}\right.$ 电流密度下循环 2000 周后比容量高达 $\left.197 \mathrm{mAh} \cdot \mathrm{g}^{-1}\right)$. Zhao 等 ${ }^{[105]}$ 利用卤虫囊肿贝壳为碳源和氮 源, $\mathrm{H}_{3} \mathrm{PO}_{4}$ 为磷源制备了 $\mathrm{N} / \mathrm{P}$ 共掺杂硬碳, 展现出高达 $336 \mathrm{mAh} \cdot \mathrm{g}^{-1}$ 的比容量. Huang 等 ${ }^{[106]}$ 以橡树种子为原料, 一步碳化制备了天然 $\mathrm{S} / \mathrm{P}$ 共掺杂的硬碳, 得到了 $1 \mathrm{~A} \cdot \mathrm{g}^{-1}$ 电流密度下高达 $136.1 \mathrm{mAh}^{\circ} \mathrm{g}^{-1}$ 的比容量. Peng 等 ${ }^{[107]}$ 以 葡萄糖水热制备的碳球为前驱体，与 $\left(\mathrm{NH}_{4}\right)_{2} \mathrm{HPO}_{4}$ 混合 高温碳化, 制备了 N/P 共掺杂的硬碳负极, 得益于 N/P 共掺引入了大量的缺陷位点，同时增大了层间距，极大 
地促进了 $\mathrm{Na}^{+}$的传输和存储, 得到了 $5 \mathrm{~A} \cdot \mathrm{g}^{-1}$ 电流密度下 高达 $136 \mathrm{mAh} \cdot \mathrm{g}^{-1}$ 的比容量. $\mathrm{Yu}$ 等 ${ }^{[108]}$ 采用冷冻干燥将 $\mathrm{NH}_{4} \mathrm{HB}_{4} \mathrm{O}_{7} \cdot \mathrm{H}_{2} \mathrm{O}$ 与细菌纤维素混合, 经高温碳化, 制备 了 $\mathrm{B} / \mathrm{N}$ 共掺杂的碳负极(BN-CNFs), 获得了 $100 \mathrm{~mA} \cdot \mathrm{g}^{-1}$ 电流密度下循环 120 周后高达 $581 \mathrm{mAh} \cdot \mathrm{g}^{-1}$ 的比容量以 及卓越的循环稳定性 $\left(10 \mathrm{~A} \cdot \mathrm{g}^{-1}\right.$ 电流密度下循环 1000 周 比容量高达 $277 \mathrm{mAh} \cdot \mathrm{g}^{-1}$ ), 结合 DFT 计算研究发现 B/N 共掺杂可以带来协同效应: 增大层间距从而促进钠离子 的层间嵌入, 以及提升电化学活性和电子导电性(图 3). $\mathrm{Cai}$ 等 ${ }^{[109]}$ 采用自上而下的方法将块体几丁质剥离成 $2 \mathrm{D}$ 纳米片, 制备了 $\mathrm{N} / \mathrm{O}$ 共掺杂的硬碳负极, 获得了优异的 倍率性能 $\left(10 \mathrm{~A} \cdot \mathrm{g}^{-1}\right.$ 电流密度下高达 $102 \mathrm{mAh} \cdot \mathrm{g}^{-1}$ 的比容 量)和卓越的循环稳定性 $5 \mathrm{~A} \cdot \mathrm{g}^{-1}$ 电流密度下循环 10000 周后仍有 $140 \mathrm{mAh} \cdot \mathrm{g}^{-1}$ 的稳定比容量. $\mathrm{Fu}$ 等 ${ }^{[110]}$ 利用可规 模化的固相合成法合成了 $\mathrm{S} / \mathrm{Se} / \mathrm{N}$ 三元共掺杂硬碳负极, 获得了优异的倍率性能, $10 \mathrm{~A} \cdot \mathrm{g}^{-1}$ 电流密度下展现出高 达 $125.9 \mathrm{mAh} \cdot \mathrm{g}^{-1}$ 的比容量, 通过动力学分析证明了优 异的倍率性能主要是由于共掺杂引入的电容性 $\mathrm{Na}$ 存储. $\mathrm{Li}$ 等 ${ }^{[111]}$ 利用银柳花为前驱体, 一步碳化制备了天然 $\mathrm{N} / \mathrm{P} / \mathrm{S}$ 共掺杂的硬碳, $1 \mathrm{~A} \cdot \mathrm{g}^{-1}$ 电流密度下展现出高达 201 $\mathrm{mAh} \cdot \mathrm{g}^{-1}$ 的比容量.

近年来, 阳离子掺杂也被研究发现有改善硬碳储钠 性能的功效. 掺杂 $\mathrm{Li} / \mathrm{Na}$, 也称为预锂化/预钠化技术, 可以有效降低不可逆容量, 显著提升首周库伦效率. Pol
等 ${ }^{[112]}$ 采用滴落涂布法将钠粉末分散到碳电极中，实现 预钠化，使首周不可逆库伦效率从 $19.3 \%$ 降低到 $8 \%$. Qian 等 ${ }^{[113]}$ 开发出一种简单的利用二苯胺钠进行化学预 钠化的方法, 可以快速实现硬碳预钠化, 得到了非常令 人满意的 $100 \%$ 的库伦效率和长循环稳定性, $100 \mathrm{~mA} \cdot \mathrm{g}^{-1}$ 电流密度下循环 1000 周几乎没有任何容量损失; 与 $\mathrm{Na}_{3} \mathrm{~V}_{2}\left(\mathrm{PO}_{4}\right)_{3}$ 正极组成的全电池也表现出高达 $95 \%$ 的 $\mathrm{ICE}$ (图 3). $\mathrm{Wu}$ 和 $\mathrm{Bai}$ 等 ${ }^{[14]}$ 通过直接裂解椰壳制备了天 然钾掺杂的硬碳负极, 得益于其天然高含量的钾掺杂, 其层间距达到 $0.4 \mathrm{~nm}$, 极大地促进了钠离子的存储和扩 散, 得到了 $314 \mathrm{mAh} \cdot \mathrm{g}^{-1}$ 的比容量和循环 200 周后高达 $92 \%$ 的容量保持率. 此后, $\mathrm{Wu}$ 和 Bai 等 ${ }^{[115]}$ 通过裂解罗望 子果壳制备了天然富 $\mathrm{Ca}$ 的硬碳负极, 并通过调节热解 温度获得了最优化的结构, 得到了 $326.7 \mathrm{mAh} \cdot \mathrm{g}^{-1}$ 的比 容量和 $70.39 \%$ 的首周库伦效率. 这些研究为探索生物 质中天然存在的阳离子对硬碳材料的性能影响提供了 思路.

调控含氧官能团也是一种有效调控硬碳储钠性能 的手段. 含氧官能团会改变材料的表面和体相结构、电 导率、润湿性和反应活性等，进而影响界面 SEI 膜的形 成和储钠性能. 预氧化是一种非常简单的引入含氧官能 团的方法, $\mathrm{Hu}$ 等 ${ }^{[116]}$ 通过预氧化引入含氧基官能团实现 了沥青碳化后结构从有序到无序的转变,可逆容量从 94 $\mathrm{mAh} \cdot \mathrm{g}^{-1}$ 增加到 $300.6 \mathrm{mAh} \cdot \mathrm{g}^{-1}$, 首周库仑效率从 $64.2 \%$
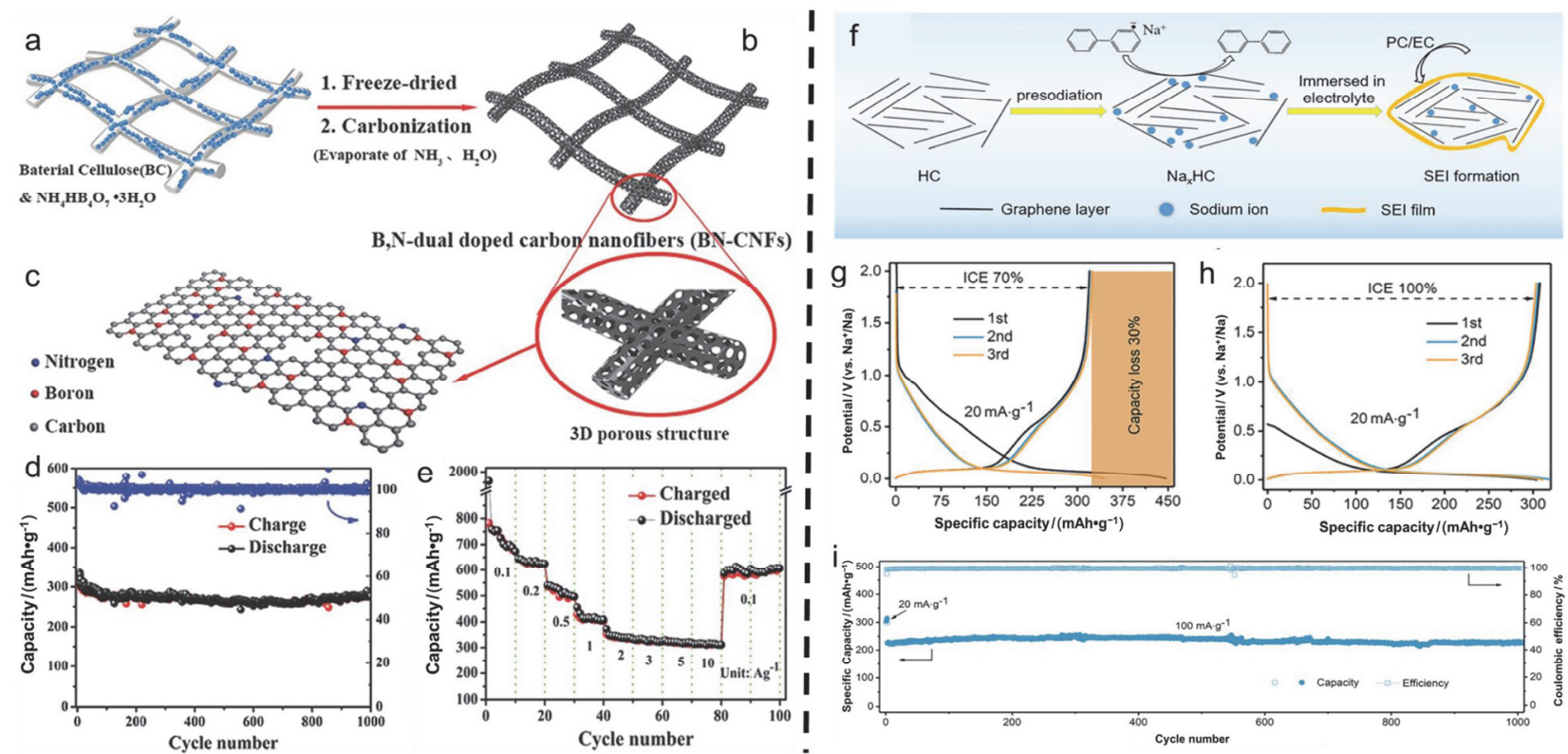

图 $3(\mathrm{a}, \mathrm{b}, \mathrm{c}) \mathrm{BN}-\mathrm{CNF}$ 电极的合成过程示意图, (d) BN-CNFs 电极在 $10 \mathrm{~A} \cdot \mathrm{g}^{-1}$ 电流密度下的长循环性能, (e) 倍率性能 ${ }^{[108]}$. 已获得参考文献[108] 的转载许可, 版权所有 $(2017$ The Authors. Published by WILEY-VCH Verlag GmbH \& Co. KGaA, Weinheim. (f) 化学预钠化和随后形成 SEI 膜的过 程示意图. $20 \mathrm{~mA} \cdot \mathrm{g}^{-1}$ 电流密度下前三周充放电曲线 $\left(\mathrm{g}\right.$ )原始电极和(h) $\mathrm{NaxHC}$ 电极, (i) $\mathrm{NaxHC}$ 电极在 $100 \mathrm{~mA} \cdot \mathrm{g}^{-1}$ 电流密度下的长循环, 电压区间 $0 \sim 2 \mathrm{~V}$ vs. $\mathrm{Na}^{+} / \mathrm{Na}^{[113]}$. 已获得参考文献[113]的转载许可, 版权所有〔 2020 American Chemical Society

Figure $3(\mathrm{a}, \mathrm{b}, \mathrm{c})$ Fabrication process of BN-CNFs electrode, (d) cycling performance of BN-CNFs at a high current density of $10 \mathrm{~A} \cdot \mathrm{g}^{-1}$, (e) rate performance $^{[108]}$. Reprinted with permission from ref. [108]. Copyright, (C) 2017 The Authors. Published by WILEY-VCH Verlag GmbH \& Co. KGaA, Weinheim. (f) Schematic illustration of chemical presodiation and the subsequent SEI formation process on HC anodes. The initial three cycles of charge-discharge curves for (g) pristine $\mathrm{HC}$ and (h) NaxHC electrodes at a constant current of $20 \mathrm{~mA} \cdot \mathrm{g}^{-1}$. (i) Long-cycling performance of the NaxHC electrode at $100 \mathrm{~mA} \cdot \mathrm{g}^{-1}$ in the voltage range of $0 \sim 2 \mathrm{~V}$ vs. Na ${ }^{+} / \mathrm{Na}^{[113]}$. Reprinted with permission from ref. [113]. Copyright $\mathbb{C} 2020$ American Chemical Society 
提升到 $88.6 \%$. 氧的引入诱发沥青结构的相互交联, 从 而阻止了高温碳化过程中沥青的熔化与有序重排, 起到 了抑制其石墨化进程的作用; 此外, 高温过程中释放出 的气体小分子如 $\mathrm{CO} 、 \mathrm{CO}_{2}$ 等会进一步改变碳材料的微 结构, 起到了双重调控的作用, 最终产生了沥青碳化后 的无序结构, 而无序结构的产生使其既具有斜坡容量又 具有平台容量, 从而显著增加了储钠容量. Liu 等 ${ }^{[117]}$ 以 无烟煤为碳源, 通过预碳化结合干冰辅助的机械化学工 艺获得了高含量羧基精准嫁接 $(20.12 \%)$ 的储钠碳材料, 展现出优异的钠离子储存性能和循环稳定性, $30 \mathrm{~mA} \cdot \mathrm{g}^{-1}$ 电流密度下的容量可达 $382 \mathrm{mAh} \cdot \mathrm{g}^{-1}$; 即使在 $2 \mathrm{~A} \cdot \mathrm{g}^{-1}$ 的 高电流密度下容量也能达到 $152 \mathrm{mAh} \cdot \mathrm{g}^{-1}$, 循环 2000 次 后保持率超过 $80 \%$. 进一步的结合电化学动力学分析, DFT 理论计算, 以及原位 XRD 分析揭示了羧基官能团 既能通过其与 $\mathrm{Na}^{+}$的静电相互作用强化表面吸附储存钠 过程, 也能通过增加钠化过程中碳片层间的排斥力强化 嵌入储钠过程, 因而能够有效提升储钠比容量和倍率性 能.

\section{2 形貌设计}

钠离子由于具有较大的原子半径, 所以具有缓慢的 动力学, 所以研究者们通过形貌设计来增加扩散通道、 缩短扩散距离, 从而进行倍率性能优化. 例如 $0 \mathrm{D}$ 碳量 子点、1D 碳纤维、2D 碳纳米片、3D 碳球、碳框架等, 以 及空心结构、多孔结构、分级结构等 ${ }^{[118-136]}$. 一些研究 者利用一些生物质碳源具有特殊形貌的特性来进行形 貌设计，例如 Huang 等 ${ }^{[118]}$ 用 $\mathrm{H}_{3} \mathrm{PO}_{4}$ 处理柚子皮合成了 多孔硬碳材料, 其形貌显示出连接的孔结构, 具有 1272 $\mathrm{m}^{2} \cdot \mathrm{g}^{-1}$ 的高比表面积, 此外含 $\mathrm{O} / \mathrm{P}$ 的功能团可以引发赝 电容吸附贡献容量, 在 $0.2 \mathrm{~A} \cdot \mathrm{g}^{-1}$ 电流密度下循环 220 周 后仍有 $181 \mathrm{mAh} \cdot \mathrm{g}^{-1}$ 的比容量, 同时, 在 $5 \mathrm{~A} \cdot \mathrm{g}^{-1}$ 电流密 度下其比容量高达 $71 \mathrm{mAh} \cdot \mathrm{g}^{-1}$, 然而其大的比表面积和 较多的官能团导致了其首周库伦效率只有 $27 \%$. $\mathrm{Hu}$ 等 ${ }^{[119]}$ 利用棉花制备了一维微米管状硬碳(HCT), 用于钠 离子电池负极时在 $0.03 \mathrm{~A} \cdot \mathrm{g}^{-1}$ 电流密度下得到了 315 $\mathrm{mAh} \cdot \mathrm{g}^{-1}$ 的高比容量和 $83 \%$ 的首周库伦效率以及优异的 循环稳定性(图 4 所示). Guo 等 ${ }^{[120]}$ 以木棉纤维为前驱体 制备了微纳米管, 该微纳结构具有比表面积低、 $\mathrm{Na}^{+}$扩 散路径短的优势, 用作钠离子电池负极时展现出 $80 \%$ 的 首周库仑效率和 $290 \mathrm{mAh} \cdot \mathrm{g}^{-1}$ 的可逆容量. Cao 等 ${ }^{[121]}$ 以 废纸为碳源, 制备了超细硬碳纤维, 展现了 319.6 $\mathrm{mAh} \cdot \mathrm{g}^{-1}$ 的高比容量, 循环 100 周后容量保持率高达 99.3\%. Tian 等 ${ }^{[122]}$ 选用蘑菇狍子制备了硬碳纳米盘, 用 作钠离子电池负极展现了 $305.8 \mathrm{mAh} \cdot \mathrm{g}^{-1}$ 的比容量, 0 $0.1 \mathrm{~V}$ 的平台区容量高达 $188.0 \mathrm{mAh} \cdot \mathrm{g}^{-1}$.

此外, 人为合成一些特殊形貌的硬碳负极也进行了 广泛尝试, 例如利用模板法(软/硬模板法)制备多孔或空 心结构, 设计分级结构等. White 等 ${ }^{[123]}$ 以聚苯乙烯为软 模板，以葡萄糖为碳源，水热法制备碳球前驱体，经过 后续高温碳化过程聚苯乙烯分解形成空心碳球, 得到了 $10 \mathrm{~A} \cdot \mathrm{g}^{-1}$ 大电流密度下仍具有高达 $50 \mathrm{mAh} \cdot \mathrm{g}^{-1}$ 比容量的 优异倍率性能(图 4 所示). Cao 等 ${ }^{[124]}$ 通过热解聚苯胺制 备了空心碳纳米线, 展现了杰出的倍率性能, $0.5 \mathrm{~A} \cdot \mathrm{g}^{-1}$ 电流密度下可逆比容量高达 $149.9 \mathrm{mAh} \cdot \mathrm{g}^{-1}$. Zhao 等 ${ }^{[125]}$ 设计制备了 $\mathrm{N}$ 掺杂的双壳层空心硬碳球，直径接近 400
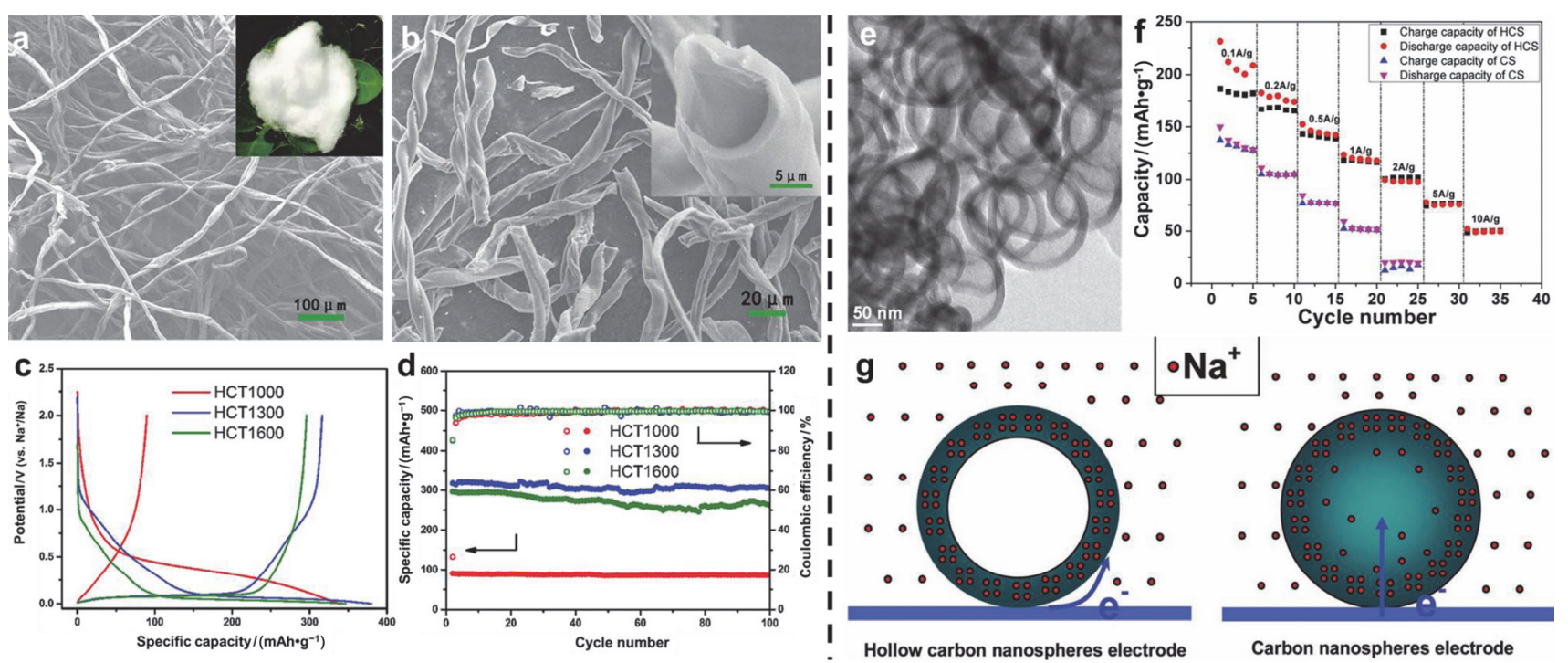

图 4 (a, b) 棉花和碳化后的棉花的 SEM 图像, (c, d) HCT 样品的充放电曲线和循环性能 ${ }^{[119]}$. 已获得参考文献[119]的转载许可, 版权所有(C) 2016 WILEY-VCH Verlag GmbH \& Co. KGaA, Weinheim. (e) 制备的空心碳球的 SEM 图像, (f) 倍率性能, (g)空心碳纳米球和碳球的电化学反应过程示 意图 ${ }^{[123]}$. 已获得参考文献[123]的转载许可, 版权所有(C) 2012 WILEY-VCH Verlag GmbH \& Co. KGaA, Weinheim

Figure 4 (a, b) SEM images of cotton and carbonized cotton, (c, d) charge-discharge curves and cycle performance of HCT samples ${ }^{[119]}$. Reprinted with permission from ref. [119]. Copyright (C) 2016 WILEY-VCH Verlag GmbH \& Co. KGaA, Weinheim. (e) SEM images of the prepared hollow carbon nanospheres, (f) rate performance, (g) schemes of the electrochemical reaction process of hollow carbon nanospheres and carbon spheres ${ }^{[123]}$. Reprinted with permission from ref. [123]. Copyright $(2) 2012$ WILEY-VCH Verlag GmbH \& Co. KGaA, Weinheim 
$\mathrm{nm}$, 壳层厚度约 $20 \mathrm{~nm}$. 独特的结构有利于电解液的浸 润和 $\mathrm{Na}^{+}$的快速存储, 从而通过高速率的赝电容过程获

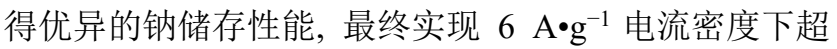
过 $113 \mathrm{mAh} \cdot \mathrm{g}^{-1}$ 高比容量. 与块体硬碳材料相比, 这种 空心结构倍率性能非常突出，这得益于空心结构增加了 电极/电解液接触面积、增加了储钠活性位点, 同时这种 薄壁结构极大地缩短了扩散路径. 为了进一步提升 $\mathrm{Na}^{+}$ 传输速度, 研究者们利用造孔剂(F127 $7^{[126]} 、 \mathrm{NaCl}^{[127-128]}$ 、 $\mathrm{NaHCO}_{3}{ }^{[129]} 、 \mathrm{MoO}_{2}{ }^{[130]} 、 \mathrm{CaCO}_{3}{ }^{[131]}$ 等)构造多孔形貌增 加扩散通道, 减小扩散距离. $\mathrm{Yu}$ 等 ${ }^{[126]}$ 以聚丙烯腈为碳 源, F127 为模板, 通过静电纺丝法制备了多孔碳纤维负 极, $0.5 \mathrm{~A} \cdot \mathrm{g}^{-1}$ 电流密度下循环 1000 周后可逆比容量仍高 达 $140 \mathrm{mAh} \cdot \mathrm{g}^{-1}$. 此后 $\mathrm{Yu}$ 等 ${ }^{[127]}$ 以 $\mathrm{NaCl}$ 为造孔剂, 沥青 和酚醛树脂为碳源合成了三维多孔无定型碳材料, 用作 钠离子电池负极材料时展现出优异的倍率性能(9.6 $\mathrm{A} \cdot \mathrm{g}^{-1}$ 电流密度下比容量高达 $\left.66 \mathrm{mAh} \cdot \mathrm{g}^{-1}\right)$. Wu 和 Bai 等 ${ }^{[128]}$ 开发了熔融盐造孔的方法制备具有交联多孔结构 的硬碳材料, 壳聚糖和氯化钠溶液冷冻干燥后高温碳 化, 在高温碳化过程中, 氯化钠熔融蒸发过程留下了丰 富的相互交联的孔道, 这种独特的交联多孔结构硬碳展 现出了优异的储钠倍率性能, $2 \mathrm{~A} \cdot \mathrm{g}^{-1}$ 电流密度下可逆容
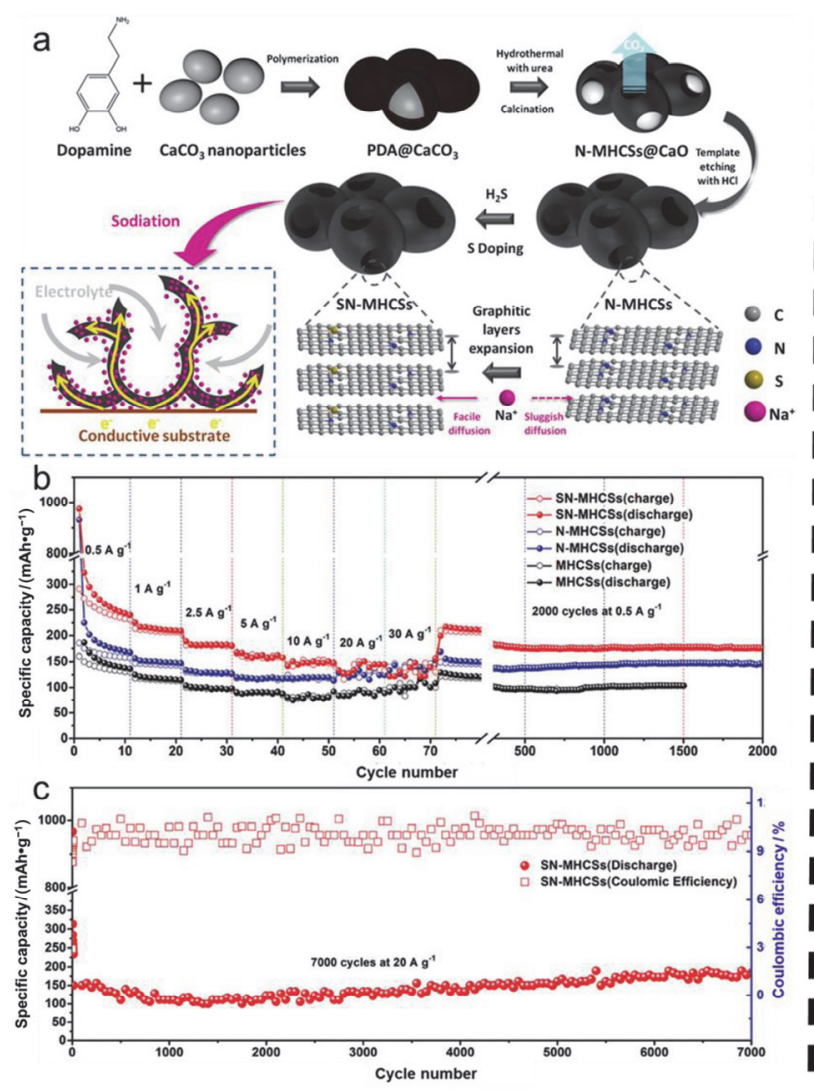

量高达 $239.8 \mathrm{mAh} \cdot \mathrm{g}^{-1}$. 这些多孔结构碳材料优异的倍 率性能得益于多孔结构有效增加了扩散通道，缩短了扩 散距离, 增加了电解液与电极材料的接触, 提高电解液 浸润性; 此外, 设计分级孔道结构有利于平衡大比表面 积增加储钠活性位点但会造成电解液过度分解之间的 矛盾, 能够在提升倍率性能的同时不牺牲首周库伦效 率. Sun 等[131]结合了中空结构和多孔结构的优势, 以聚 多巴胺为碳源, $\mathrm{CaCO}_{3}$ 为模板, 制备了 $\mathrm{S} / \mathrm{N}$ 共掺杂的介 孔中空碳球(SNMHCSs), 在 $20 \mathrm{~A} \cdot \mathrm{g}^{-1}$ 大电流密度下循环 7000 周后比容量增加至 $180 \mathrm{mAh} \cdot \mathrm{g}^{-1}$ (图 5 所示), 其相 互连接的介孔结合空心结构促进了 $\mathrm{Na}^{+}$和电子以及电解 液的快速传输, 缓冲了循环过程中的体积变化, 从而得 到了高倍率性能和循环稳定性. 此外, 将材料纳米化也 可以有效提升倍率性能, 但纳米化带来的大比表面积增 加了 SEI 膜的形成和副反应发生的概率, 降低了首周库 伦效率，而设计分级结构可以有效地平衡倍率性能和 ICE 之间的矛盾. $\mathrm{Ji}$ 等 ${ }^{[132]}$ 合成了碳量子点并在高温下通 过自组装合成了 3D 多孔碳框架, 用于钠电负极时表现 出超高的倍率性能和循环稳定性, 在 10 和 $20 \mathrm{~A} \cdot \mathrm{g}^{-1}$ 电流 密度下比容量分别高达 104 和 $90 \mathrm{mAh} \cdot \mathrm{g}^{-1}, 5 \mathrm{~A} \cdot \mathrm{g}^{-1}$ 电流 密度下循环 10000 周几乎没有容量衰减. 其优异的性能
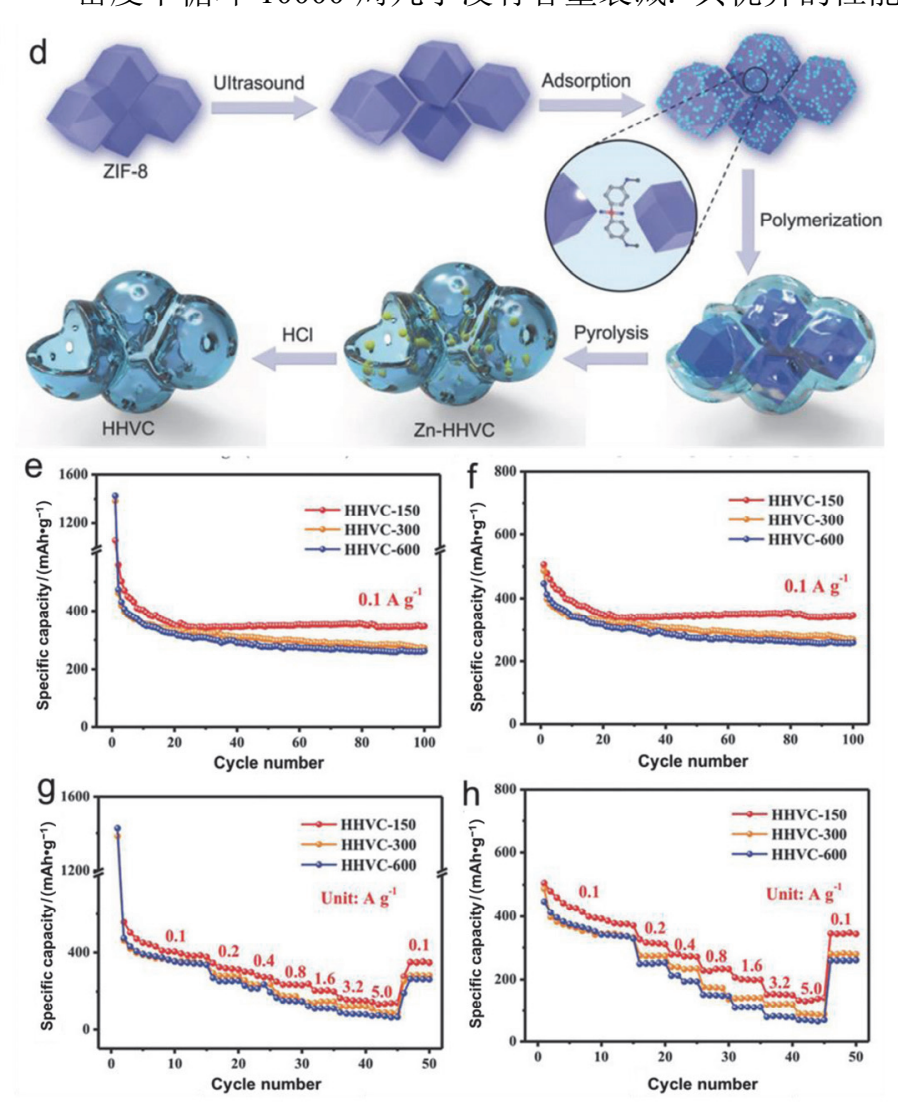

图 5 (a) SNMHCSs 的合成过程, (b) 倍率性能, (c) $20 \mathrm{~A} \cdot \mathrm{g}^{-1}$ 电流密度下 SNMHCSs 的循环性能 ${ }^{[131]}$. 已获得参考文献[131]的转载许可, 版权所有(C) 2019 WILEY-VCH Verlag GmbH \& Co. KGaA, Weinheim. (d) HHVC 的合成过程, (e, f) 不同 HHVC 样品的放电/充电循环性能, (g, h) 倍率性能 [133]. 已获得参考文献[133]的转载许可, 版权所有( 2018 The Authors. Published by WILEY-VCH Verlag GmbH \& Co. KGaA, Weinheim

Figure 5 (a) The synthesis process of SNMHCSs, (b) rate performance, (c) cycle performance of SNMHCSs at the current density of $20 \mathrm{~A} \cdot \mathrm{g}^{-1}[131]$. Reprinted with permission from ref. [131]. Copyright (C) 2019 WILEY-VCH Verlag GmbH \& Co. KGaA, Weinheim. (d) The synthesis process of HHVC, (e, $\mathrm{f})$ discharge/charge cycle performance of different HHVC samples, $(\mathrm{g}, \mathrm{h})$ rate performance of different HHVC samples ${ }^{[133]}$. Reprinted with permission from ref. [133]. Copyright (C) 2018 The Authors. Published by WILEY-VCH Verlag GmbH \& Co. KGaA, Weinheim 
得益于其独特的形貌, 3D 结构和大比表面积促进了电 解液对电极的浸润以及 $\mathrm{Na}^{+}$的传输; 此外, 其多孔结构 有利于缓解储钠造成的体积膨胀, 同时贡献电容性吸附 容量. 此后, Ji 等 ${ }^{[133]}$ 采用表面聚合法又合成了 $\mathrm{S} / \mathrm{P} / \mathrm{N}$ 共 掺杂分级囊泡状结构碳负极(HHVC), 用作钠离子电池 负极时, $5 \mathrm{~A} \cdot \mathrm{g}^{-1}$ 电流密度下比容量高达 $142.6 \mathrm{mAh} \cdot \mathrm{g}^{-1}$ (图 5 所示), 这得益于分级囊泡状结构具有快速离子/电 子传输过程, 同时杂原子掺杂增加了层间距, 增强了电 子导电性等协同作用优化了其性能. Shi 等 ${ }^{[134]}$ 巧妙地通 过溶剂诱导相分离的方法制备了具有多通道的硬碳纤 维, 通过简单地调整可溶性聚合物和不可溶性碳前驱体 的质量比可以精确设计通道结构从而影响纳米碳纤维 的微观结构. 得益于活性位点的增加和电极动力学的增 强, 制备的多通道碳纳米纤维用作自支撑负极时表现出 非常高的倍率性能, $2 \mathrm{~A} \cdot \mathrm{g}^{-1}$ 电流密度下比容量高达 88.1 $\mathrm{mAh} \cdot \mathrm{g}^{-1}$. Jian 等 ${ }^{[135]}$ 以葡萄糖为碳源, 通过在水热过程 中添加聚苯乙烯磺酸钠作为表面活性剂使直径较小的 碳球聚集成具有合理结构的二次颗粒堆积结构, 小球形 成的大比表面积可以提供丰富的储钠活性位点, 小球堆 积形成的丰富的中孔和大孔结构有利于电解液的运输, 缩短了 $\mathrm{Na}^{+}$的扩散路径, 并缓冲了循环过程中的体积膨 胀. 这些结构优势使制备的硬碳负极展现出优异的倍率 性能和循环稳定性, $10 \mathrm{~A} \cdot \mathrm{g}^{-1}$ 的超高电流密度下循环 10000 周, 比容量高达 $140 \mathrm{mAh} \cdot \mathrm{g}^{-1}$. 多孔或多通道结构 以及空心结构虽然可以增加扩散通道或减小扩散距离, 从而促进 $\mathrm{Na}^{+}$的快速扩散, 提升倍率性能, 但是这也带 来了体积比容量的降低, 不利于全电池的体积能量密 度. 设计合理的分级结构可以在保障倍率性能的同时保 障体积能量密度, 是一种值得进一步研究的优化方式.

\section{3 界面构造}

电极与电解液接触的界面往往对电解液的分解过 程有很大影响, 从而影响 SEI 膜的厚度和稳定性以及界 面阻抗等, 进而对首周库伦效率、钠离子的扩散动力学 和循环稳定性产生较大影响, 这促使研究者们通过界面 构造来进行性能优化. 通常采用的有表面包覆、氧化物 覆盖缺陷等方式. $\mathrm{Hu}$ 等 ${ }^{[137]}$ 以庶糖水热制备碳球, 高温 碳化过程中通入甲苯, 甲苯在硬碳表面裂解形成软碳包 覆, 将首周库伦效率从 $54 \%$ 提升到 $83 \%$, 同时获得了 93\%的容量保持率(循环 100 周). Wang 等 ${ }^{[138]}$ 在活性炭表 面以励青为原料进行软碳包覆, 获得了 $80 \%$ 的首周库伦 效率以及循环 100 周后高达 $97 \%$ 的容量保持率. Titirici 等 ${ }^{[139]}$ 以滤纸为硬碳前驱体, 沥青为软碳前驱体, 制备 了软碳包覆的硬碳负极, 利用软碳堵塞了硬碳的部分孔 洞, 阻碍了电解液在孔洞内分解形成 SEI 膜, 使首周库 伦效率提高到 $80 \%$, 同时提高了电极的循环稳定性(图 6). 近期, Cao 等[140]利用原子层沉积技术在硬碳表面沉 积了一层均匀且极薄的 $\mathrm{Al}_{2} \mathrm{O}_{3}$ 薄膜, 一方面有效抑制了 电解液的分解, 提高了首周库伦效率和电极稳定性; 另
一方面有效降低了界面电阻和电极过电位，从而提升了 倍率性能. 界面构造显著改善了电解液过度分解的情 况, 形成了更加均匀且稳定的 SEI 膜, 从而有效地提升 了首周库伦效率和循环稳定性，但对于倍率性能的改善 却并不显著, 究其原因主要是因为界面构造虽然减小了 SEI 膜的厚度, 降低了界面阻抗, 有利于钠离子从电解 液传输到材料内部, 但钠离子在电解液和材料内部中的 传输动力学并未得到有效改善.

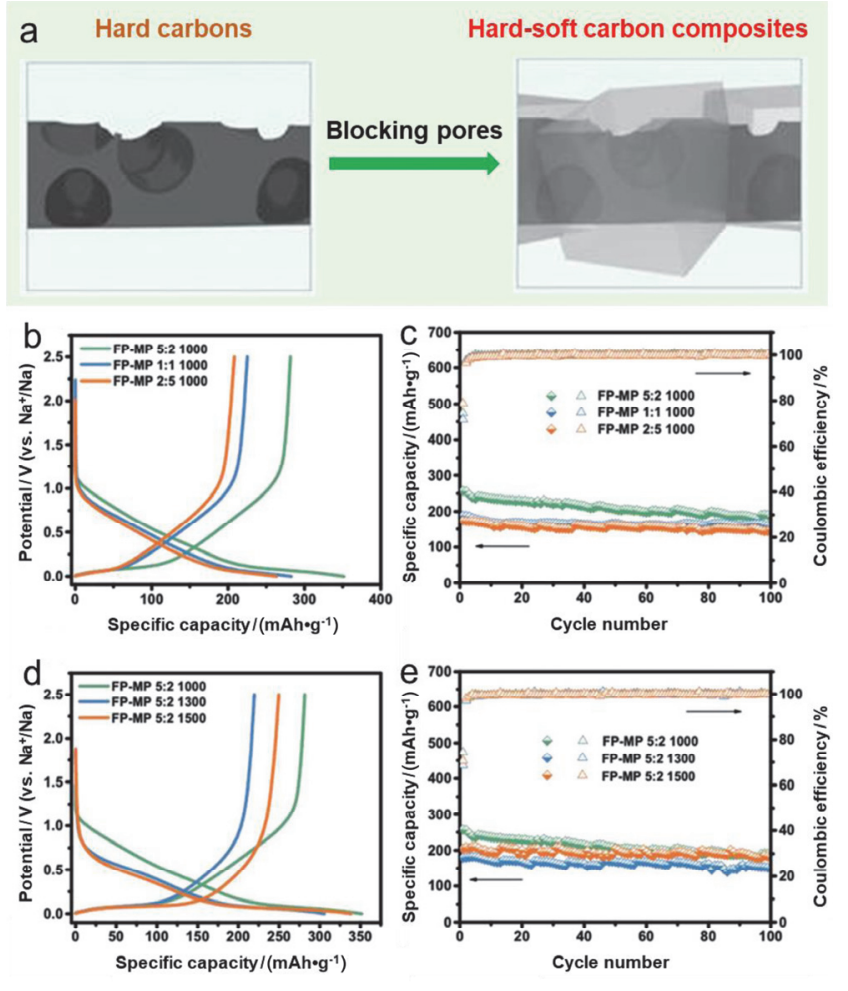

图 6 (a) 软碳填堵硬碳孔示意图, (b, c) 不同沥青含量制备的硬-软碳 复合物的充放电曲线和循环性能, (d, e) 不同温度制备的软硬碳复合 电极的充放电曲线和循环性能 ${ }^{[139]}$. 已获得参考文献[139]的转载许可, 版权所有 (C) 2019 WILEY-VCH Verlag GmbH \& Co. KGaA, Weinheim

Figure 6 (a) Scheme of the pores in hard carbon filled by soft carbon, $(b, c)$ initial discharge/charge profiles and cycle performance of all the hard-soft carbon composites with different asphalt contents, $(d, e)$ initial discharge/charge profiles and cycle performance of all the hard-soft carbon composites with different carbonized temperatures ${ }^{[139]}$. Reprinted with permission from ref. [139]. Copyright (C) 2019 WILEY-VCH Verlag $\mathrm{GmbH} \& \mathrm{Co}$. KGaA, Weinheim

\section{4 电解液优化}

近年来大量针对硬碳负极性能优化的研究工作主 要集中在硬碳材料本身的改性方面, 但这些研究往往表 现出了首周库伦效率和倍率性能优化无法兼得的塩㸱 结果. 直到 2017 年, Zhou 等 ${ }^{[141]}$ 将醚类电解液与生物质 硬碳匹配，发现在醚类电解液中硬碳负极展现出了远高 于在酯类电解液中的首周库伦效率、平台容量和倍率性 能. 这一发现引起研究者们广泛关注, 开始针对硬碳负 极和醚类电解液匹配这一体系展开探索. 研究发现, 酯 类电解液应用于钠离子电池体系时形成的分解产物的 
溶解度高于锂离子电池体系 ${ }^{[142]}$, 因此钠离子电池体系 中难以形成完整且有效的 SEI 膜, 大量针对碳材料负极 的研究都证明了这点. 然而, 形成能有效保护电极的 SEI 膜对电池的循环稳定性和可逆性至关重要, 因此对 负极表面 SEI 膜的有效修饰是迫切需要的. 醚类电解液 是一种典型的非质子溶剂型电解液, 而几乎所有的极性 非质子溶剂在接近 $0 \mathrm{~V}\left(\mathrm{vs} . \mathrm{Na} / \mathrm{Na}^{+}\right)$时会发生不可逆地 分解形成 SEI 膜. 醚类电解液对无定型碳负极材料的 SEI 膜的有效修饰最先被 Yang 等 ${ }^{[143]}$ 证明, 当具有大比 表面积的还原氧化石墨烯和醚类电解液( NaOTf in DEGDME) 匹配时, 展现出高于酯类电解液( $\mathrm{NaOTf}$ in $\mathrm{EC} / \mathrm{DEC}$ )近两倍的首周库伦效率, 并且研究发现醚类电 解液分解在负极表面形成的 SEI 膜与酯类电解液中形成 的 SEI 膜对比具有更稳定、更薄、更紧凑、更均匀的特 点, 证明醚类电解液能够对大比表面积的无定型碳负极 材料的 SEI 膜起到有效修饰的作用, 有效提高首周库伦 效率、倍率性能和循环稳定性. 相对于还原氧化石墨烯, 硬碳材料一般比表面积较小, 匹配醚类电解液也可以起 到修饰 SEI 膜的作用, 从而获得较高的首周库伦效率, 同时, 醚类电解液很大程度上促进了 $\mathrm{Na}^{+}$的传输动力学, 从而显著提高了倍率性能, 但令人遗憾的是, 对于长循 环的稳定性没有保护作用. Zhou 等 ${ }^{[141]}$ 以丝瓜啐为为原料 得到生物质硬碳材料, 研究其在酯类 $\left(\mathrm{NaClO}_{4}(\mathrm{NaCO})\right.$ in $\mathrm{EC} / \mathrm{DEC})$ 和醚类 $(\mathrm{NaOTf}$ in TEGDME) 电解液中的不同电 化学特性(图 7), 并且发现大电流密度下由于在酯类电解 液中会发生较大的极化现象导致平台容量的快速衰减造 成倍率性能较差, 而醚类电解液中 $\mathrm{Na}^{+}$依然能够快速传 输, 有效减弱极化现象, 大电流密度下依然有较高的平台 容量, 从而具有更好的倍率性能; 同时, 首周库伦效率也 由酯类电解液中的 $41 \%$ 提高到 $63 \%$; 然而 $2.1 \mathrm{~A} \cdot \mathrm{g}^{-1}$ 电流 密度下循环 2000 周后醚类电解液中容量保持率却只有 $39 \%$, 低于酯类电解液的 $56 \%$, 说明在硬碳负极表面醚类 电解液分解得到的 SEI 膜的稳定性需要进一步提升. 针对 硬碳负极在醚类电解液中长循环稳定性的问题, $\mathrm{Xu}$ 等 ${ }^{[144]}$ 提出了一个新颖的解决方法, 通过预先在酯类电解液 $\left(\mathrm{NaPF}_{6}\right.$ in $\left.\mathrm{EC} / \mathrm{DEC}\right)$ 中循环形成较完整的 SEI 膜, 然后在 醚类电解液 $\left(\mathrm{NaPF}_{6}\right.$ in $\left.\mathrm{DEGDME}\right)$ 中循环时, 预先形成的 SEI 膜非常稳定, 从而起到了有效的保护作用, 获得非常 高的循环稳定性, $500 \mathrm{~mA} \cdot \mathrm{g}^{-1}$ 电流密度下循环 1000 周后 都未发生明显的容量衰减; 同时结合了醚类电解液中 $\mathrm{Na}^{+}$ 的快速传输动力学特性, 获得了较高的倍率性能. 为了进 一步提高首周库伦效率, Balbuena 等 ${ }^{[145]}$ 以商业化硬碳为 原料, 通过预锂化来进一步提高首周库伦效率, 并且通过 实验结合模拟的方法探究了不同电解液体系形成的 SEI 膜如何决定钠离子存储动力学, 研究发现使用醚类电解 液 $\mathrm{NaClO}_{4}$ in TEGDME) 调节 SEI 膜结合预锂化得到的硬 碳负极展现出 $92.1 \%$ 的首周库伦效率, $1 \mathrm{~A} \cdot \mathrm{g}^{-1}$ 电流密度下 循环 1000 次后容量保持率超 $90 \%$; 预锂化得到的硬碳负
极与磷酸钒钠 $\left(\mathrm{Na}_{3} \mathrm{~V}_{2}\left(\mathrm{PO}_{4}\right)_{3}, \mathrm{NVP}\right)$ 正极组装的全电池也展 现出优异的电化学性能, 首周比容量高达 $98.2 \mathrm{mAh} \cdot \mathrm{g}^{-1}$ (基于正极活性物质质量计算), 50 次循环后比容量高达 $81.8 \mathrm{mAh} \cdot \mathrm{g}^{-1}$ (图 8). 基于 $\mathrm{Na}^{+}$在醚类电解液体系中具有 非常优异的动力学特性, $\mathrm{Xu}$ 等 ${ }^{[146]}$ 以壳聚糖为原料得到硬 碳材料, 制备了不同负载量的电极, 研究发现醚类电解液 $\left(\mathrm{NaPF}_{6}\right.$ in $\left.\mathrm{DME}\right)$ 有更高的离子电导和更大的钠离子扩散 系数, 在 $17 \mathrm{mg} \cdot \mathrm{cm}^{-2}$ 的超高负载量下, 仍可获得 4.3 $\mathrm{mAh} \cdot \mathrm{cm}^{-2}$ 的可逆面积比容量, 进一步促进了其商业化应 用(图9). 结合形貌设计和醚类电解液双重优势, $\mathrm{Wu}$ 等 ${ }^{[147]}$ 设计了具有自交织结构的柔性自支撑硬碳纸负极(HCP), 在醚类电解液(NaOTf in DEGDME) 中实现了高达 $91.2 \%$ 的首周库伦效率, 兼具高倍率性能、超长循环寿命和出色 的低温性能，具有很大的实际应用潜力(图 10). Yu 等 ${ }^{[148]}$ 以细菌纤维素膜为原料, 直接碳化制备了柔性自支撑多 孔碳纤维膜负极, 在醚类电解液(NaOTf in DEGDME)中 展现出超高的首周库伦效率, $0.2 \mathrm{~A} \cdot \mathrm{g}^{-1}$ 电流密度下高达 $93 \%$, 并且具有超长的循环寿命, 在 $10 \mathrm{~A} \cdot \mathrm{g}^{-1}$ 的电流密度 下, 循环 10000 周仍有 $105 \mathrm{mAh} \cdot \mathrm{g}^{-1}$ 的比容量. 这两种自 支撑电极避免了导电炭和粘结剂的加入对比容量和首周 库伦效率造成的损耗，同时简化了电极的制备工艺，为
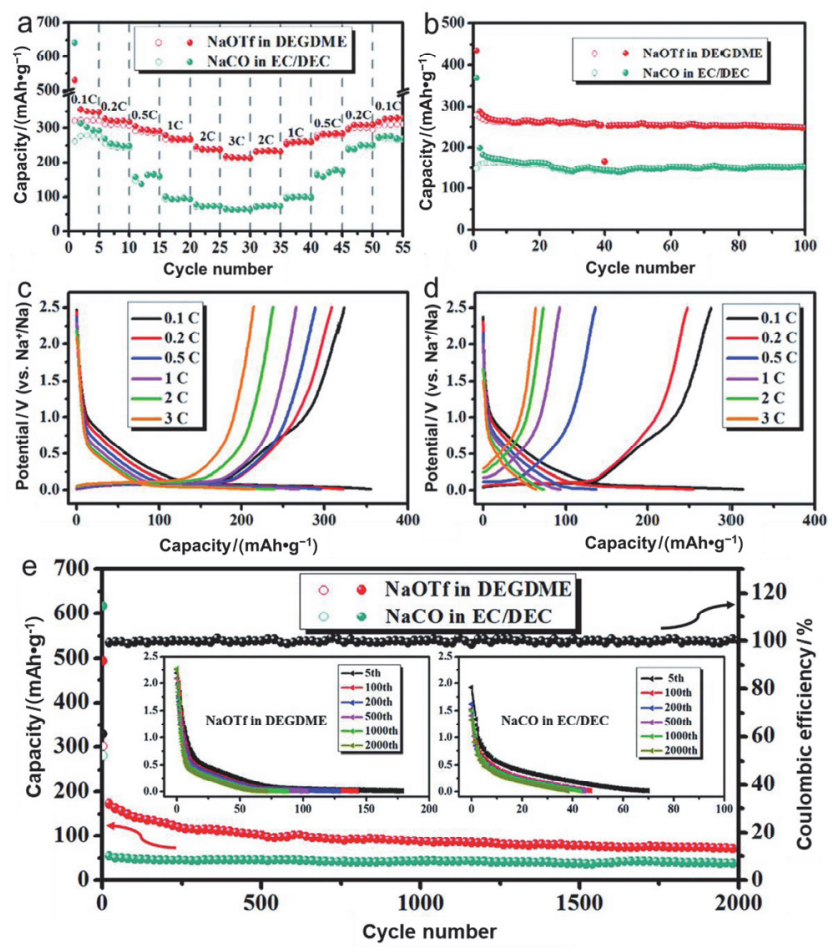

图 7 不同电解液中硬碳负极的电化学性能. (a) 倍率性能, (b) 30 $\mathrm{mA} \cdot \mathrm{g}^{-1}$ 电流密度下的循环性能, (c, d) 不同电流密度下的充放电曲线, (e) $2.1 \mathrm{~A} \cdot \mathrm{g}^{-1}$ 电流密度下的长循环性能 ${ }^{[141]}$. 已获得参考文献[141]的转 载许可, 版权所有(C The Royal Society of Chemistry 2017

Figure 7 The electrochemical performances of hard carbon anode in different electrolyte. (a) Rate performance, (b) cycle performance at 30 $\mathrm{mA} \cdot \mathrm{g}^{-1},(\mathrm{c}, \mathrm{d})$ initial discharge/charge profiles at different current densities, (e) long cycle performance at $2.1 \mathrm{~A} \cdot \mathrm{g}^{-1}[141]$. Reprinted with permission from ref. [141]. Copyright $\odot$ The Royal Society of Chemistry 2017 

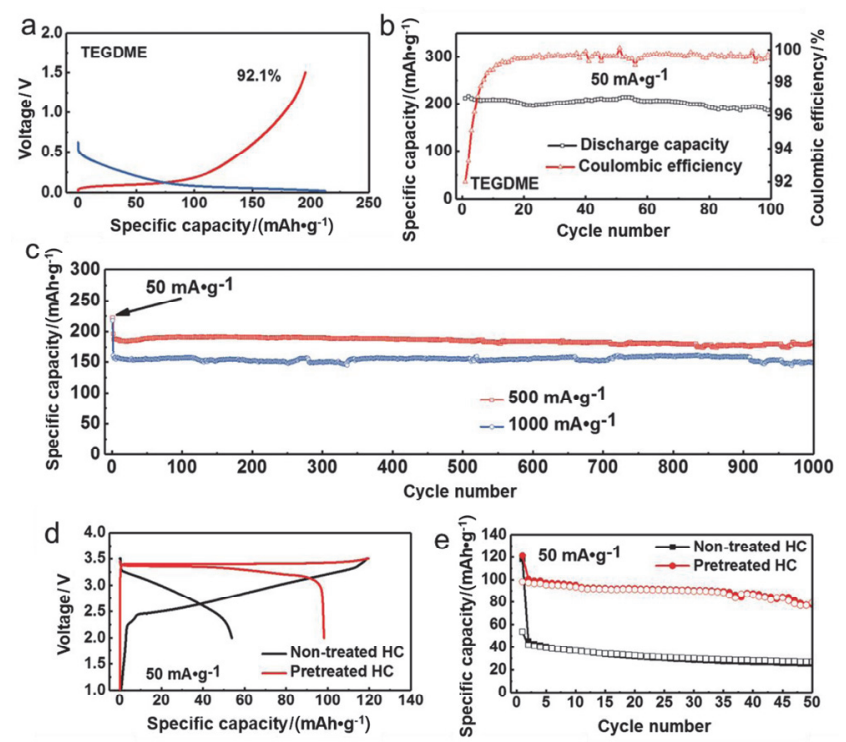

图 8 (a) 预锂化硬碳负极在 $50 \mathrm{~mA} \cdot \mathrm{g}^{-1}$ 电流密度下的充放电曲线, (b) 预锂化硬碳负极在 $50 \mathrm{~mA} \cdot \mathrm{g}^{-1}$ 电流密度下的循环性能, (c) 预锂化硬碳 负极在 500 和 $1000 \mathrm{~mA} \cdot \mathrm{g}^{-1}$ 电流密度下的长循环性能, (d) 预锂化硬碳 负极和 NVP 正极组装的全电池的充放电曲线, (e) 全电池的循环性 能 ${ }^{[145]}$. 已获得参考文献 [145] 的转载许可, 版权所有 (C) 2018 WILEY-VCH Verlag GmbH \& Co. KGaA, Weinheim

Figure 8 (a) Initial discharge/charge profiles of pretreated hard carbon anode at $50 \mathrm{~mA} \cdot \mathrm{g}^{-1}$, (b) cycling performance of pretreated $\mathrm{HC}$ anode at a current density of $50 \mathrm{~mA} \cdot \mathrm{g}^{-1}$, (c) long-term cycling performance of pretreated $\mathrm{HC}$ at high current densities of 500 and $1000 \mathrm{~mA} \cdot \mathrm{g}^{-1}$, (d) full cell charge/discharge curves of NVP with pretreated and non-pretreated $\mathrm{HC}$, (e) cycling performance of the full cell ${ }^{[145]}$. Reprinted with permission from ref. [145]. Copyright (C) 2018 WILEY-VCH Verlag GmbH \& Co. $\mathrm{KGaA}$, Weinheim
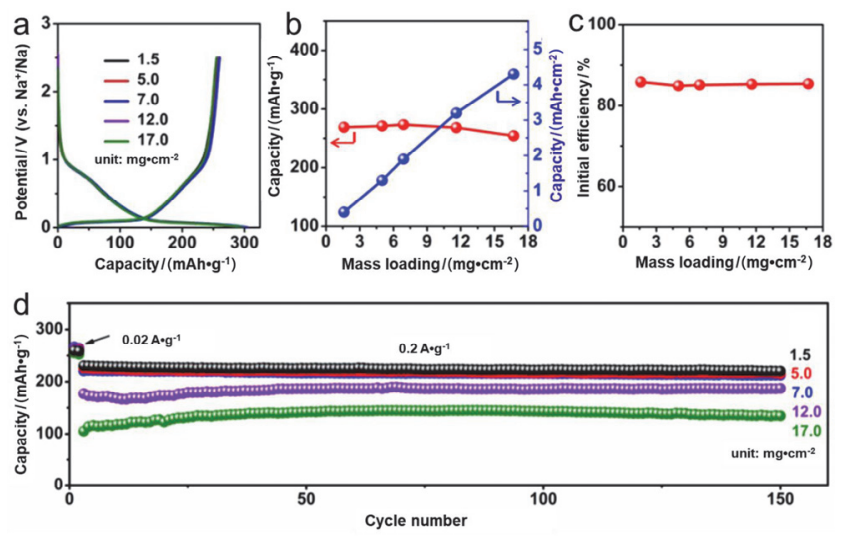

图 9 不同负载量硬碳负极在醚类电解液中的电化学性能: (a) 0.02 $\mathrm{A} \cdot \mathrm{g}^{-1}$ 电流密度下的充放电曲线, (b) 质量比容量和面积比容量随负载 量的变化曲线, (c) 首周库伦效率随负载量的变化曲线, (d) $0.2 \mathrm{~A} \cdot \mathrm{g}^{-1}$ 电流密度下的长循环 ${ }^{[146]}$. 已获得参考文献[146]的转载许可, 版权所 有(C) 2018, American Chemical Society

Figure 9 Electrochemical performance of the $\mathrm{HC}$ anodes with different mass loadings with the ether-based electrolyte: (a) discharge/charge profiles at a current density of $0.02 \mathrm{~A} \cdot \mathrm{g}^{-1}$, (b) gravimetric and areal specific capacities change curves with mass loading, (c) initial Coulombic efficiencies change curve with mass loading, and (d) cycling performance at a current density of $0.2 \mathrm{~A} \cdot \mathrm{g}^{-1}[146]$. Reprinted with permission from ref. [146]. Copyright (C) 2018, American Chemical Society
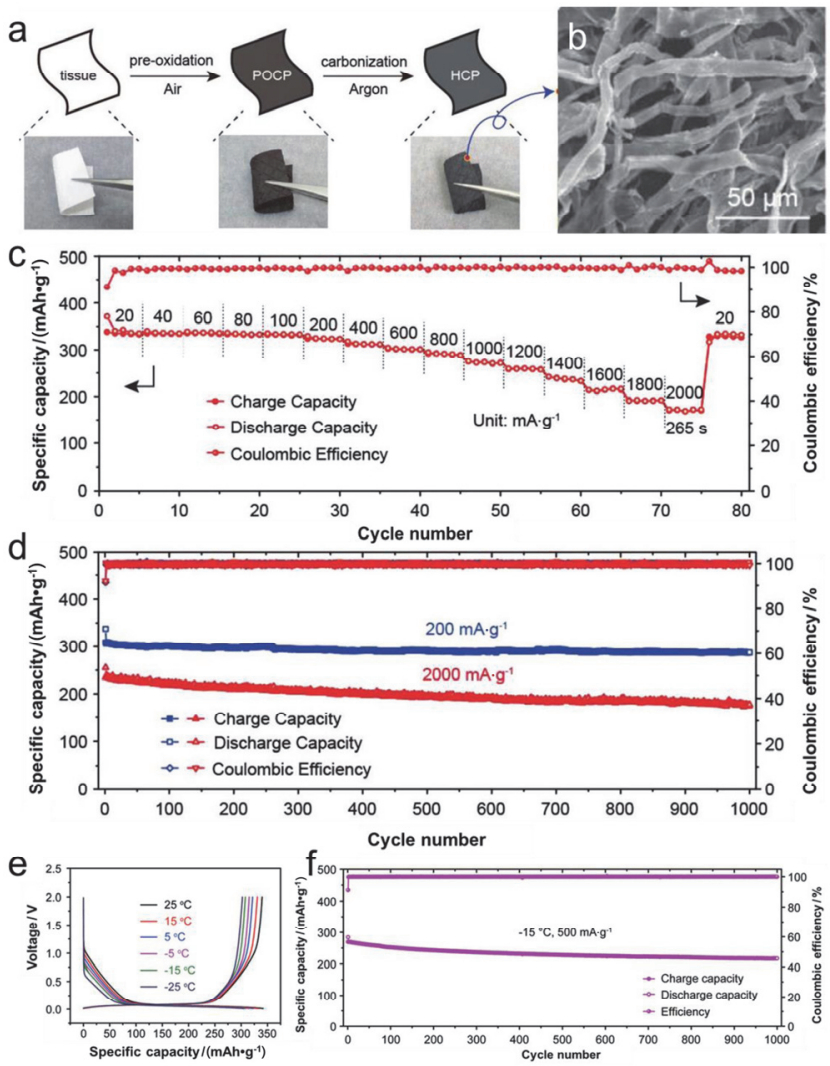

图 10 (a) HCP 的合成过程示意图, 薄纸, 预氧化碳纸, 硬碳纸的数 码照片均显示出柔性自支撑的特征, (b) HCP 的 SEM 图片, (c) HCP 在 20 到 $2000 \mathrm{~mA} \cdot \mathrm{g}^{-1}$ 范围内不同电流密度下的倍率性能, (d) HCP 在 200 和 $2000 \mathrm{~mA} \cdot \mathrm{g}^{-1}$ 电流密度下的长循环性能, (e) HCP 在 $50 \mathrm{~mA} \cdot \mathrm{g}^{-1}$ 电流 密度下 -25 到 $25{ }^{\circ} \mathrm{C}$ 范围内的充放电曲线, (f) $\mathrm{HCP}$ 在 $500 \mathrm{~mA} \cdot \mathrm{g}^{-1}$ 电流 密度下 $-15{ }^{\circ} \mathrm{C}$ 下的长循环性能 ${ }^{[147]}$. 已获得参考文献[147]的转载许 可, 版权所有 (C) 2019 WILEY - VCH Verlag GmbH \& Co. KGaA, Weinheim

Figure 10 (a) Schematic illustration of the preparation procedure for HCP and the digital photos of tissue, preoxidation carbonaceous paper (POCP) and HCP showing their flexible and self-supporting characteristics, (b) SEM image of HCP, (c) rate capability at various current densities from 20 to $2000 \mathrm{~mA} \cdot \mathrm{g}^{-1}$ of $\mathrm{HCP}$, (d) long-term cycling performance at 200 and $2000 \mathrm{~mA} \cdot \mathrm{g}^{-1}$ of HCP, (e) GCD curves of $50 \mathrm{~mA} \cdot \mathrm{g}^{-1}$ of HCP at the temperature range from -25 to $25{ }^{\circ} \mathrm{C}$, (f) long-term cyclic stability of $\mathrm{HCP}$ at $-15{ }^{\circ} \mathrm{C}$ and $500 \mathrm{~mA} \cdot \mathrm{g}^{-1}$ [147]. Reprinted with permission from ref. [147]. Copyright (C) 2019 WILEY - VCH Verlag GmbH \& Co. $\mathrm{KGaA}$, Weinheim

发展柔性电极提供了思路. 近期, $\mathrm{Wu}$ 和 Bai 等[149]针对硬 碳负极在醚基电解液中为何会有比酯基电解液中优异的 倍率性能这一问题进行了研究, 作者从电解液中的离子 迁移动力学, 电极/电解液的界面电化学特性和电极材料 中的离子扩散动力学三方面对硬碳在醚基电解液中的储 钠动力学进行了全面的分析, 发现硬碳在醚基电解液中 快速储钠动力学可归因于三个方面: (1) 与酯基电解液相 比，醚基电解液中的溶剂化钠离子具有更高的迁移速率; (2) 醚基电解液分解形成的 SEI 膜无机组分更多, 且更薄, 使得界面处的 SEI 膜阻抗和电荷转移阻抗更小; (3) 醚基 电解液中是 $\mathrm{Na}^{+} /$solvated $\mathrm{Na}^{+}$共存储的方式, 在电极中具 有更高的离子扩散系数, 此外, 溶剂化 $\mathrm{Na}^{+}$的存储避免了 缓慢的脱溶过程, 同时可以显著增加层间距, 激发嵌入噟 
电容行为. 三方面协同作用显著提升了硬碳负极在醚基 电解液中的储钠动力学(图 11).
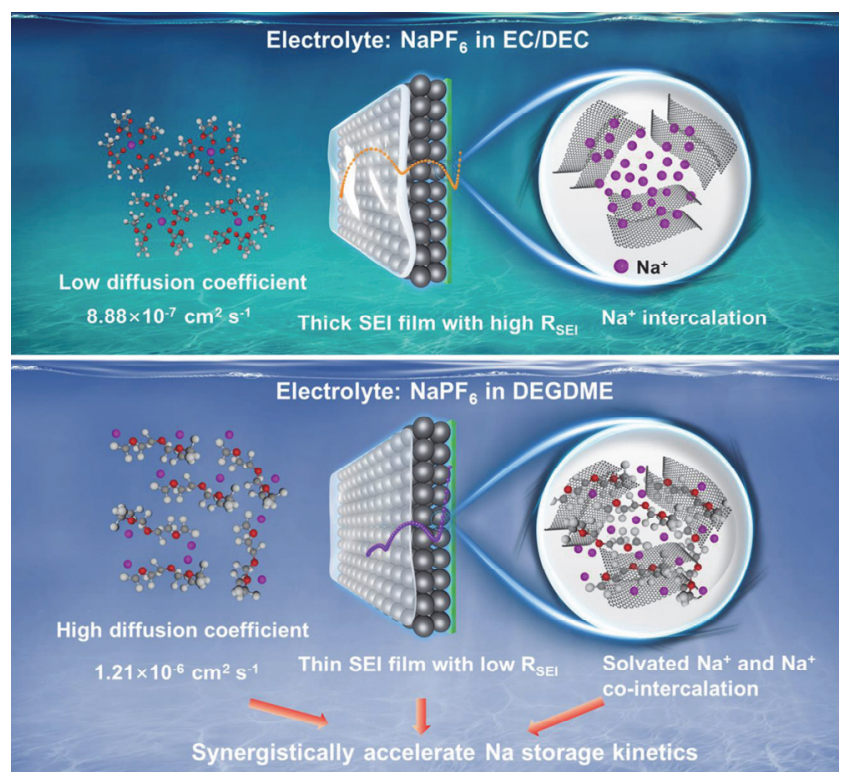

图 11 硬碳负极在醚基电解液中的快速储钠动力学机制示意图 ${ }^{[149]}$. 已获得参考文献 [149]的转载许可, 版权所有 (C) 2021 Wiley-VCH $\mathrm{GmbH}$

Figure 11 Schematic illustration of the fast Na storage kinetics in HC with ether electrolyte ${ }^{[149]}$. Reprinted with permission from ref. [149]. Copyright $\mathbb{C} 2021$ Wiley-VCH GmbH

\section{4 实用化的问题和挑战}

钠离子电池主要面向大规模储能领域, 所以需要满 足大规模储能电池的基本要求, 即低成本、长寿命和高 安全性. 作为一种可供选择的钠离子电池负极材料, 硬 碳也应该满足低成本、长寿命和高安全性的需求. 虽然 众多的性能优化方法已经被证明可以有效改善硬碳负 极的电化学性能, 但是其在规模化应用方面仍然有一些 问题需要进一步的考虑, 开发具有高度一致性、低成本、 高首效、高比容量、高倍率及长循环寿命的优质硬碳材 料依然面临着诸多挑战. 此外, 硬碳平台区储钠电位在 $0.1 \mathrm{~V}$ 以下, 接近钠沉积的电位, 硬碳表面是否会形成 钠枝晶威胁电池安全需要更多的关注.

\section{1 结构一致性和成本问题}

钠离子电池用于大规模储能系统必然需要将单体 电池进行组合使用. 如果电极材料本身结构一致性较差 的话, 单体电池会出现电压、容量及其衰减率、内阻及 其充放电过程中随时间变化率、寿命、自放电率等性能 参数上的差别. 这些差别不但对组合后的电池组荷电状 态(state of charge, SOC)的判断有所影响, 更重要的是影 响电池组性能发挥和循环寿命, 而且极可能会引发安全 问题 ${ }^{[150]}$. 因此, 保障材料结构一致性是保障电池系统 循环寿命和安全性的基础. 硬碳材料的结构依赖于前驱 体的状态和碳化工艺, 只有保障前驱体具有高度一致
性, 碳化过程中受热非常均匀才能使最终得到的硬碳材 料的一致性得到保障. 生物质前驱体虽然具有低成本的 优势, 但其往往含有较多的杂原子, 且杂原子的分布并 不均匀, 此外, 不同产地、不同批次的生物质并不具有 一致性, 这导致碳源的选择上很难选择某种生物质前驱 体直接碳化实现大规模制备高品质的硬碳. 因此, 发展 低成本的生物质硬碳应该考虑碳化前处理工艺来保障 前驱体的一致性, 从而保障碳化过程中硬碳的结构发展 具有一致性. 有机高分子聚合物作为硬碳的碳源时, 可 以结合特定的合成方法得到具有特殊形貌的硬碳材料, 能够避免杂质，保障结构的一致性，然而，合成工艺往 往较为复杂, 且极大地增加了硬碳的制造成本, 并不太 适合大规模的生产. 生物质衍生物, 例如纤维素、木质 素、蔗糖和葡萄糖等, 具有较低的成本且不含有杂质, 可以平衡成本和硬碳的结构一致性问题, 比较适合大规 模生产高品质硬碳. 此外, 硬碳的碳化工艺和碳化设备 也应进一步探索，保障大批量制备硬碳时能够受热均 匀, 从而保障碳化后的硬碳结构具有高度一致性.

\section{2 低的首周库伦效率和循环寿命问题}

钠离子电池如果应用于储能领域, 应该具有可以和 磷酸铁锂电池相近的能量密度和循环寿命. 目前硬碳的 比容量大多超过 $300 \mathrm{mAh} \cdot \mathrm{g}^{-1}$, 一些甚至超过 400 $\mathrm{mAh} \cdot \mathrm{g}^{-1}$, 具有可和商用锂离子电池石墨负极相较的比 容量 ${ }^{[63]}$. 但目前报道的硬碳负极首周库伦效率通常较 低，在酯基电解液中大多在 $50 \% \sim 80 \%$ 左右，少数超过 $80 \%$; 在醚基电解液中通常在 $80 \%$ 90\%左右，目前最 高的报道达到了 $93 \%$ 的首周库伦效率 ${ }^{[148]}$. 而商用化锂 离子电池石墨负极首周库伦效率通常超过 $95 \%$. 虽然提 升碳化温度或者表面包覆可以减少表面缺陷，从而提升 首周库伦效率, 但提升效果有限. 预钠化是一种非常有 效地提升首周库伦效率的手段, 开发简单且安全、低成 本和适合大规模应用的预钠化方法是非常重要的.

此外, 硬碳负极的循环稳定性也有待进一步提升. 硬碳的长循环性能主要是受到电解质/电极界面稳定性 的影响, 不稳定的界面是造成容量衰减的主要原因. $\mathrm{Hu}$ 等 ${ }^{[1511}$ 将循环后的硬碳电极加入新的电解液后其容量得 以恢复, 证明了硬碳充电/放电循环中的容量损失不是 由于微观结构的不可逆破坏. Younesi 等 ${ }^{[152]}$ 研究了硬碳 表面 SEI 组分在酯电解质中的溶解度. 基于同步辐射的 硬 X 射线光电子能谱测试, 证明钠离子电池中硬碳表面 形成的 SEI 膜大部分会发生溶解, 稳定性较锂离子电池 中形成的 SEI 膜差, 钠离子电池硬碳电极表面的针化不 够充分. 因此, 要从根本上解决硬碳负极的循环稳定性 问题就需要构建稳定的、钝化充分的界面. 这可以一方 面从人为预先构建稳定的钝化层来实现, 另一方面, 优 化电解液组分, 形成不易溶解的稳定的 SEI 膜也能够有 效提升循环寿命. 


\section{3 安全问题}

硬碳储钠存在一个明显的平台区, 储钠电位在 0.1 $\mathrm{V}$ 以下，且具有储钠长平台的硬碳负极更能够有效提升 全电池的平均工作电压和能量密度, 但是 $0.1 \mathrm{~V}$ 以下的 平台区电位接近钠沉积的电位, 硬碳表面是否会因为局 部过电位而发生金属钠沉积进而形成钠枝晶? 钠枝晶 是否会刺穿隔膜威胁电池安全? 目前对于这些问题的 研究有待深入. 近期, Britton 等 ${ }^{[153]}$ 利用原位 ${ }^{1} \mathrm{H}$ 和 ${ }^{23} \mathrm{Na}$ 核磁共振成像技术对硬碳负极在脱嵌钠过程中钠离子 的分布进行了直接观测. ${ }^{23} \mathrm{Na}$ 核磁共振光谱揭示了金属 $\mathrm{Na}$ 和准金属 $\mathrm{Na}$ 在充电循环中的发展变化, 这些变化与 硬碳电极中的嵌钠相关. 此外, 研究人员在钠离子全电 池中观察到了金属态 $\mathrm{Na}$ 的信号, 并分析了钠枝晶在硬 碳过钠化过程中的演化. 该工作提供了一种检测硬碳表 面钠枝晶的方法, 但缺乏钠枝晶对钠离子电池的安全性 影响的研究. 硬碳表面钠枝晶生长带来的潜在安全隐患 亟需深入的研究.

\section{4 实用化前景}

目前, 全球已经有 20 余家公司进行了钠离子电池 产业化布局, 其中 FARADION、NAIADES、中科海纳、 钠创新能源这四家公司是目前全球比较领先的钠离子 技术及产品的研发公司. 这些公司采用的技术路线几乎 都是基于硬碳负极, 如表 1 所示. 近期, 宁德时代也推 出了首款钠离子电池, 负极侧也是选择了硬碳材料, 能 量密度达到了 $160 \mathrm{Wh} \cdot \mathrm{kg}^{-1}$. 随着钠离子电池产业化的 不断推进, 硬碳材料也将会有非常大的市场需求. 此外, 硬碳负极与石墨负极相比, 在冷启动及快速充电模式中 更具有优势, 所以硬碳材料在锂离子电池领域也非常具 有应用前景. 目前, 全球能够生产高端硬碳材料的企业 较少, 而随着钠离子电池产业化的推进, 对硬碳材料的 市场需求将逐渐增加, 所以未来需要更多的企业和研究 机构来共同推进硬碳负极材料的研发工作.

表 1 钠离子电池产业化情况

Table 1 Industrialization of sodium ion batteries

\begin{tabular}{|c|c|c|}
\hline 公司 & 技术路线 & 电池性能 \\
\hline $\begin{array}{l}\text { FARADION } \\
\text { (英国) }\end{array}$ & $\begin{array}{l}\text { 层状氧化物正极/硬碳负极/ } \\
\text { 有机电解液, 软包电池 }\end{array}$ & $\begin{array}{l}\text { 能量密度 } 150 \sim 160 \mathrm{Wh} \cdot \\
\mathrm{kg}^{-1} \text {, 循环寿命超 } 3000 \\
\text { 次 }\end{array}$ \\
\hline $\begin{array}{l}\text { NAIADES } \\
\text { (法国) }\end{array}$ & $\begin{array}{l}\text { 氟磷酸钒钠正极/硬碳负极/ } \\
\text { 有机电解液, 圆柱电池 }\end{array}$ & $\begin{array}{l}\text { 能量密度 } 90 \mathrm{Wh} \cdot \mathrm{kg}^{-1} \text {, } \\
\text { 循环寿命 } 4000 \text { 次 }\end{array}$ \\
\hline $\begin{array}{l}\text { 中科海纳 } \\
\text { (中国) }\end{array}$ & $\begin{array}{l}\text { 层状氧化物正极/无定型碳负 } \\
\text { 极/有机电解液, 软包电池和 } \\
\text { 圆柱电池 }\end{array}$ & $\begin{array}{l}\text { 能量密度接近 } 150 \mathrm{Wh} \cdot \\
\mathrm{kg}^{-1} \text {, 循环寿命 } 4500 \text { 次 } \\
\text { 以上 }\end{array}$ \\
\hline $\begin{array}{l}\text { 钠创新能源 } \\
\text { (中国) }\end{array}$ & $\begin{array}{l}\text { 层状氧化物正极/硬碳负极/ } \\
\text { 有机电解液, 软包电池 }\end{array}$ & $\begin{array}{l}\text { 能量密度 } 120 \mathrm{Wh} \cdot \mathrm{kg}^{-1} \text {, } \\
\text { 循环寿命 } 1000 \text { 次 }\end{array}$ \\
\hline $\begin{array}{l}\text { 宁德时代 } \\
\text { (中国) }\end{array}$ & $\begin{array}{l}\text { 普鲁士蓝正极/硬碳负极/有 } \\
\text { 饥电解液 }\end{array}$ & 能量密度 $160 \mathrm{Wh} \bullet \mathrm{kg}^{-1}$ \\
\hline
\end{tabular}

\section{5 结论}

钠离子电池硬碳负极作为一种来源广泛、绿色环保
的材料非常有希望实现实用化. 然而，其实用化过程中 面对着首周库伦效率低、循环稳定性不足和倍率性能差 等问题. 要实现实用化, 硬碳负极应该具有低成本、高 比容量、高倍率、高首效以及长循环稳定等特性. 近年 来, 为了制备出高水平的硬碳材料, 研究者们采用结构 调控、形貌设计和界面构造等改性方法对硬碳负极的性 能进行优化, 但由于缺陷对首周库伦效率和倍率性能是 相反的作用，而难以做到同时将其首周库伦效率和倍率 性能提升到较高的水平. 醚类电解液的复兴则很好地解 决了首周库伦效率和倍率性能无法兼顾的问题, 获得了 令人满意的电化学性能. 虽然硬碳负极在醚类电解液中 展现出来超高的首周库伦效率和优异的倍率性能, 但醚 类电解液在电压达到 $4 \mathrm{~V}$ 时会分解, 不利于进一步提升 全电池的工作电压和能量密度, 而且梄类电解液中的循 环稳定性也需要进一步提升. 当前对硬碳的性能优化研 究已经从单纯提升电化学性能过渡到更为实际的综合 性能的优化, 需从成本、工艺和性能多方面考量, 所以 仍然有如下工作需继续深入研究:

(1)开发来源广泛的生物质衍生物碳源并结合简单 的制备方法, 获取成本低且一致性好的硬碳材料, 进一 步降低硬碳的成本. (2)开发稳定的、具有高电压特性和 钠离子快速扩散动力学特性的电解液, 结合合适的结构 调控、形貌设计和界面构造等改性方法从而提升硬碳的 倍率性能和循环稳定性. (3)开发简单且安全、低成本、 适合大规模应用的预钠化方法, 从而有效解决首周库伦 效率低的问题. (4)硬碳表面钠枝晶的生长行为对电池安 全性和循环寿命的影响进行更深入的研究. (5)实用化硬 碳负极关注的物理参数(压实密度、负载量等)对电化学 性能的影响在研究工作中应给与足够的关注.

\section{作者简介}

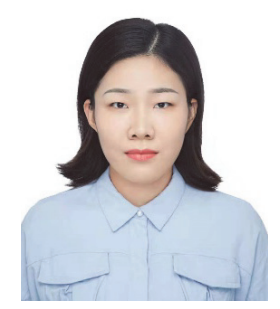

董瑞琪, 2016 年在河北工业大学获得工学学士学位, 目前 为北京理工大学材料学院博士研究生, 师从吴锋院士, 主要 研究方向为钠离子电池负极材料.

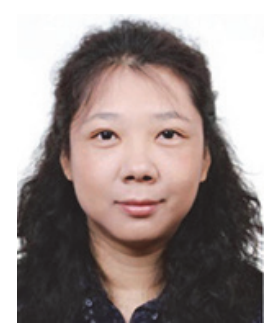

白莹, 北京理工大学材料学院教授. 研究兴趣包括锂/钠 离子电池氧化物、聚阴离子型、硅基、碳基等电极材料、凝 
胶态与固态电解质, 以及电极与电解液界面稳定性、电池热分 析与热安全等基本科学问题.

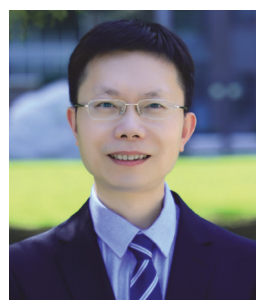

吴川, 北京理工大学材料学院教授. 长期从事先进能源 材料的研究, 关注能量储存与转化体系及其关键材料, 包括 锂离子电池、钠离子电池、铝二次电池、锂空电池、锌离子 电池及其他二次电池新体系. 任 Science 合作期刊 Energy Material Advances 副主编.

\section{References}

[1] Yabuuchi, N.; Kubota, K.; Dahbi, M.; Komaba, S. Chem. Rev. 2014, $114,11636$.

[2] Kundu, D.; Talaie, E.; Duffort, V.; Nazar, L. F. Angew. Chem. Int. Ed 2015, 46, 3431.

[3] Hwang, J. Y.; Myung, S. T.; Sun, Y. K. Chem. Soc. Rev. 2017, 46, 3529.

[4] Xiang, X. D.; Lu, Y. Y.; Chen, J. Acta Chim. Sinica 2017, 75, 154 (in Chinese). (向兴德, 卢艳莹, 陈军, 化学学报, 2017, 75, 154.)

[5] Delmas, C.; Braconnier, J. J.; Fouassier, C.; Hagenmuller, P. Solid State Ionics 1981, 3-4, 165.

[6] Tompsett, D. A.; Islam, M. S. Chem. Mater. 2013, 25, 2515.

[7] Lu, Y.; Wang, L.; Cheng, J.; Goodenough, J. B. Chem. Commun. 2012, 48, 6544.

[8] Ni, Q.; Bai, Y.; Wu, F.; Wu, C. Adv. Sci. 2017, 4, 1600275.

[9] Liu, L. L.; Qi, X. G.; Hu, Y. S.; Chen, L. Q.; Huang, X. J. Acta Chim. Sinica 2017, 75, 218 (in Chinese). (刘丽露, 戚兴国, 胡勇胜, 陈立 泉, 黄学杰, 化学学报, 2017, 75, 218.)

[10] Song, X. X.; Li, J. C.; Li, Z. H.; Li, X. F.; Ding, Y. H.; Xiao, Q. Z.; Lei, G. T. Acta Chim. Sinica 2019, 77, 625 (in Chinese). (宋学霞, 李继成, 李朝晖, 李喜飞, 丁燕怀, 肖启振, 雷钢铁, 化学学报, 2019, 77, 625.)

[11] Sato, T.; Yoshikawa, K.; Zhao, W. W.; Kobayashi, T.; Rajendra, H. B.; Yonemura, M.; Yabuuchi, N. Energy Mater. Adv. 2021, 2021, 9857563.

[12] Xie, J. S.; Xiao, Z. M.; Zuo, W. H.; Yang, Y. Acta Chim. Sinica 2021, 79, DOI: 10.6023/A21060260 (in Chinese). (谢佶晟, 肖竹梅, 左文华, 杨勇, 化学学报, 2021, 79, DOI: 10.6023/A21060260.)

[13] Xu, K. Chem. Rev. 2014, 114, 11503.

[14] Khan, M. S.; Karatrantos, A. V.; Ohba, T.; Cai, Q. Phys. Chem. Chem. Phys. 2019, 21, 22722.

[15] Eshetu, G. G.; Dieman, H. M.; Grugeon, S.; Behm, R. J.; Laruelle, S.; Armand, M.; Passerini, S. Nano Energy 2019, 55, 327.

[16] Chen, G. H.; Bai, Y.; Gao, Y. S.; Wang, Z. H.; Zhang, K.; Ni, Q.; Wu, F.; Xu, H. J.; Wu, C. ACS Appl. Mater. Interfaces 2019, 11, 43252.

[17] Chen, G. H.; Zhang, K.; Liu, Y. R.; Ye, L.; Gao, Y. S.; Lin, W. R.; Xu, H. J.; Wang, X. R.; Bai, Y.; Wu, C. Chem. Eng. J. 2020, 401, 126065.

[18] Chen, G. H.; Ye, L.; Zhang, K.; Gao, M.; Lu, H.; Xu, H. J.; Bai, Y.; Wu, C. Chem. Eng. J. 2020, 394, 10.

[19] Gao, Y. S.; Chen, G. H.; Wang, X. R.; Yang, H. Y.; Wang, Z. H.; Lin, W. R.; Xu, H. J.; Bai, Y.; Wu, C. ACS Appl. Mater. Interfaces 2020, $12,22981$.

[20] Zhu, N.; Zhang, K.; Wu, F.; Bai, Y.; Wu, C. Energy Mater. Adv. 2021, 2021, 9204217.

[21] Ma, H.; Zhang, H. R.; Xue, M. Q. Acta Chim. Sinica 2021, 79, 388 (in Chinese). (马慧, 张桓荣, 薛面起, 化学学报, 2021, 79, 388.)

[22] Zhang, Q. Q.; Lu, Y. X.; Guo, W. C.; Shao, Y. J.; Liu, L. L.; Lu, J. Z.; Rong, X. H.; Han, X. G.; Li, H.; Chen, L. Q.; Hu, Y. S. Energy Mater. Adv. 2021, 2021, 10.

[23] Liu, Y. Y.; Merinov, B. V.; Goddard, W. A. PNAS 2016, 113, 3735

[24] Jache, B.; Adelhelm, P. Angew. Chem., Int. Ed. 2014, 53, 10169.
[25] Kim, H.; Hong, J.; Park, Y. U.; Kim, J.; Hwang, I.; Kang, K. Adv. Funct. Mater. 2015, 25, 534.

[26] Zhu, Z.; Cheng, F.; Hu, Z.; Niu, Z. Q.; Chen, J. J. Power Sources 2015, 293, 626 .

[27] Wang, Z. H.; Yang, H. Y.; Liu, Y. R.; Bai, Y.; Chen, G. H.; Li, Y.; Wang, X. R.; Xu, H. J.; Wu, C.; Lu, J. Small 2020, 16, 2003268.

[28] Stevens, D.; Dahn, J. J. Electrochem. Soc. 2000, 147, 1271.

[29] Wu, L.; Hu, X.; Qian, J.; Feng, Pei.; Wu, F. Y.; Mao, R. J.; Ai, X. P.; Yang, H. X.; Cao, Y. L. Energy Environ. Sci. 2014, 7, 323.

[30] Nam, D. H.; Hong, K. S.; Lim, S. J.; Kim, M. J.; Kwon, H. S. Small $\mathbf{2 0 1 5}, 11,2885$.

[31] Sun, J.; Lee, H.; Pasta, M.; Yuan, H.; Zheng, G.; Sun, Y.; Li, Y.; Cui, Y. Nat. Nanotechnol. 2015, 10, 980.

[32] Gu, M.; Kushima, A.; Shao, Y. Y.; Zhang, J. G.; Liu, J.; Browning, N. D.; Li, J.; Wang, C. M. Nano Lett. 2013, 13, 5203.

[33] Ren, H. X.; Bai, Y.; Wang, X. R.; Ni, Q.; Wang, Z. H.; Li, Y.; Chen, G. H.; Wu, F.; Xu, H. J.; Wu, C. ACS Appl. Mater. Interfaces 2019 , 11,37812 .

[34] Ling, L. M.; Bai, Y.; Wang, Z. H.; Ni, Q.; Chen, G. H.; Zhou, Z.; Wu, C. ACS Appl. Mater. Interfaces 2018, 10, 5560.

[35] Xie, X. Q.; Makaryan, T.; Zhao, M. Q.; Van Aken, K. L.; Gogotsi, Y.; Wang, G. X. Adv. Energy Mater. 2015, 6, 1502161.

[36] Qu, B. H.; Ma, C. Z.; Ji, G.; Xu, C. H.; Xu, J.; Meng, Y.; Wang, T. H.; Lee, J. Y. Adv. Mater. 2018, 26, 3854.

[37] Chen, Q.; Sun, S.; Zhai, T.; Yang, M.; Zhao, X. Y.; Xia, H. Adv. Energy Mater. 2018, 8, 1800054.

[38] Fullenwarth, J.; Darwiche, A.; Soares, A.; Donnadieuc, B.; Monconduit, L. J. Mater. Chem. A 2014, 2, 2050.

[39] Li, P.; Liu, J.; Sun, W. Y.; Tao, Z. L.; Chen, J. Acta Chim. Sinica 2018, 76, 286 (in Chinese). (李攀, 刘建, 孙惟袜, 陶占良, 陈军, 化学学报, 2018, 76, 286.)

[40] Qian, J. F.; Xiong, Y.; Cao, Y. L.; Ai, X. P.; Yang, H. Nano Lett. 2014, 14, 1865 .

[41] Sun, D.; Zhu, X.; Luo, B.; Zhang, Y.; Tang, Y. G.; Wang, H. Y.; Wang, L. Z. Adv. Energy Mater. 2018, 8, 1801197.

[42] Li, Y.; Xu, Y. H.; Wang, Z. H.; Bai, Y.; Zhang, K.; Dong, R. Q.; Gao, Y. N.; Ni, Q.; Wu, F.; Liu, Y. J.; Wu, C. Adv. Energy Mater. 2018, 8, 1800927.

[43] Tang, C. J.; Wei, X. J.; Cai, X. Y.; An, Q.; Hu, P.; Sheng, J.; Zhu, J.; Chou, S.; Wu, L.; Mai, L. ACS Appl. Mater. Interfaces 2018, 10, 19626.

[44] Cho, J. S.; Lee, S. Y.; Kang, Y. C. Sci. Rep. 2016, 6, 23338.

[45] Li, Y.; Qian, J.; Zhang, M. H.; Wang, S.; Wang, Z. H.; Li, M. S.; Bai, Y.; An, Q. Y.; Xu, H. J.; Wu, F.; Mai, L. Q.; Wu, C. Adv. Mater. 2020, 32, 2005802.

[46] Wen, Y.; He, K.; Zhu, Y. J.; Han, F.; Xu, Y.; Matsuda, I.; Ishii, Y.; Cumings, J.; Wang, C. Nat. Commun. 2014, 5, 4033.

[47] Wang, Y.; Wang, C.; Wang, Y.; Liu, H.; Huang, Z. ACS Appl. Mater. Interfaces 2016, 8, 18860.

[48] Jian, Z.; Bommier, C.; Luo, L.; Li, Z. F.; Wang, W. T.; Wang, C. M.; Alex Greaney, P.; Ji, X. L. Chem. Mater. 2017, 29, 2314.

[49] Bai, Y.; Wang, Z.; Wu, C.; Xu, R.; Wu, F.; Liu, Y. C.; Li, H.; Li, Y.; Lu, J.; Amine, K. ACS Appl. Mater. Interfaces 2015, 7, 5598.

[50] Qu, L. P.; Ren, T.; Wang, N.; Shi, Y. L.; Zhuang, Q. C. Acta Chim. Sinica 2019, 77, 634 (in Chinese). (渠璐平, 任肜, 王宁, 史月丽, 庄全超, 化学学报, 2019, 77, 634.)

[51] Zhang, S. W.; Zhang, J.; Wu, S. D.; Lv, W.; Kang, F. Y.; Yang, Q. H. Acta Chim. Sinica 2017, 75, 163 (in Chinese). (张思伟, 张俊, 吴思 达，吕伟，康飞宇，杨全红，化学学报, 2017, 75, 163.)

[52] Cowlard, F. C.; Lewis, J. C. J. Mater. Sci. 1967, 2, 507.

[53] Bommier, C.; Luo, W.; Gao, W. Y.; Greaney, A.; Ma, S. Q.; Ji, X. L. Carbon 2014, 76, 165.

[54] Bridges, C. A.; Sun, X. G.; Zhao, J.; Paranthaman, M. P.; Dai, S. J. Phys. Chem. C 2012, 116, 7701 .

[55] Zhou, Z.; Gu, Z.; He, Y.; Peng, D.; Bao, C.; Liu, H. Int. J. Electrochem. Sci. 2019, 14, 6976.

[56] Qiu, S.; Xiao, L. F.; Sushko, M. L.; Han, K. S.; Shao, Y. Y.; Yan, M. Y.; Liang, X. M.; Mai, L. Q.; Feng, J. W.; Cao, Y. L.; Ai, X. P.; Yang, H. X.; Liu, J. Adv. Energy Mater. 2017, 7, 1700403.

[57] Komaba, S.; Murata, W.; Ishikawa, T.; Yabuuchi, N.; Ozeki, T.; Nakayama, T.; Ogata, A.; Gotoh, K.; Fujiwara, K. Adv. Funct. Mater. 2011, 21, 3859.

[58] Lu, H.; Ai, F.; Jia, Y.; Tang, C.; Zhang, X.; Huang, Y.; Yang, H.; Cao, Y. Small 2018, 14, 1802694

[59] Li, Z.; Chen, Y.; Jian, Z.; Jiang, H.; Razink, J. J.; Stickle, W. F.; 
Neuefeind, J. C.; Ji, X. Chem. Mater. 2018, 30, 4536.

[60] Sun, N.; Guan, Z.; Liu, Y. W.; Cao, Y. L.; Zhu, Q. Z.; Liu, H.; Wang, Z. X.; Zhang, P.; Xu, B. Adv. Energy Mater. 2019, 1901351.

[61] Bai, P.; He, Y.; Zou, X.; Zhao, X.; Xiong, P.; Xu, Y. Adv. Energy Mater. 2018, 8, 1703217.

[62] Zhang, B.; Ghimbeu, C. M.; Laberty, C.; Vix-Guterl, C.; Tarascon, J. M. Adv. Energy Mater. 2016, 6, 1501588.

[63] Li, Y. Q.; Lu, Y. X.; Meng, Q. S.; Jensen, A. C. S.; Zhang, Q. Q.; Zhang, Q. H.; Tong, Y. X.; Qi, Y. R.; Gu, L.; Titirici, M. M.; Hu, Y. S. Adv. Energy Mater. 2019, 1902852.

[64] Meng, Q. S.; Lu, Y. X.; Ding, F. X.; Zhang, Q. Q.; Chen, L. Q.; Hu, Y. S. ACS Energy Lett. 2019, 4, 2608.

[65] Bommier, C.; Surta, T. W.; Dolgos, M.; Ji, X. L. Nano Lett. 2015, 15,5888 .

[66] Au, H.; Alptekin, H.; Jensen, A. C. S.; Olsson, E.; O'Keefe, C. A.; Smith, T.; Crespo-Ribadeneyra, M.; Headen, T. F.; Grey, C. P.; Cai, Q.; Drew, A. J.; Titirici, M. M. Energy Environ. Sci. 2020, 13, 3469.

[67] Morikawa, Y.; Nishimura, S. I.; Hashimoto, R. I.; Ohnuma, M.; Yamada, A. Adv. Energy Mater. 2019, 10, 1903176.

[68] Wang, Z. H.; Feng, X.; Bai, Y.; Yang, H. Y.; Dong, R. Q.; Wang, X. R.; Xu, H. J.; Wang, Q. Y.; Li, H.; Gao, H. C.; Wu, C. Adv. Energy Mater. 2021, 11, 2003854.

[69] Xiao, L. F.; Lu, H. Y.; Fang, Y. J.; Sushko, M. L.; Cao, Y. L.; Ai, X. P.; Yang, H. X.; Liu, J. Adv. Energy Mater. 2018, 8, 1703238.

[70] Alvin, S.; Yoon, D.; Chandra, C.; Susantiac, R. F.; Changd, W. Y.; Ryu, C.; Kim, J. J. Power Sources 2019, 430, 157.

[71] Jin, Q. Z.; Wang, K. L.; Li, H. M.; Li, W.; Feng, P. Y.; Zhang, Z. C.; Wang, W.; Zhou, M.; Jiang, K. Chem. Eng. J. 2020, 128104.

[72] Zhang, X.; Dong, X. L.; Qiu, X.; Cao, Y. J.; Wang, C. X.; Wang, Y. G.; Xia, Y. Y. J. Power Sources 2020, 476, 228550.

[73] Ye, X. L.; Wang, H. S.; Chen, Z. F.; Li, M.; Wang, T.; Wu, C.; Zhang, J. X.; Shen, Z. X. Electrochim. Acta 2021, 371, 137776.

[74] Cong, L.; Tian, G. R.; Luo, D. X.; Ren, X. F.; Xiang, X. D. J. Electroanal. Chem. 2020, 871, 114249.

[75] Wang, Z. H.; Qie, L.; Yuan, L. X.; Zhang, W. X.; Hu, X. L.; Huang, Y. H. Carbon 2013, 55, 328.

[76] Xu, B.; Duan, H.; Chu, M.; Cao, G. P.; Yang, Y. S. J. Mater. Chem. A 2013, 1,4565 .

[77] Luo, W.; Wang, B.; Heron, C. G.; Allen, M. J.; Morre, J.; Maier, C. S.; Stickle, W. F.; Ji, X. Nano Lett. 2014, 14, 2225.

[78] Rybin, M.; Pereyaslavtsev, A.; Vasilieva, T.; Myasnikov, V.; Sokolov, I.; Pavlova, A.; Obraztsova, E.; Khomich, A.; Ralchenko, V.; Obraztsova, E. Carbon 2016, 96, 196.

[79] Boncel, S.; Pattinson, S. W.; Geiser, V.; Shaffer, M. S.; Koziol, K. K. Beilstein J. Nanotechnol. 2014, 5, 219.

[80] Wang, H. G.; Wu, Z.; Meng, F. L.; Ma, D. L.; Huang, X. L.; Wang, L. M.; Zhang, X. B. ChemSusChem 2013, 6, 56.

[81] Hao, M. Y.; Xiao, N.; Wang, Y. W.; Li, H. Q.; Zhou, Y.; Liu, C.; Qiu, J. S. Fuel Process. Technol. 2018, 177, 328.

[82] Fu, L. J.; Tang, K.; Song, K. P.; Aken, P. A.; Yu, Y.; Maier, J. Nanoscale 2014, 6, 1384

[83] Zhu, J. D.; Chen, C.; Lu, Y.; Ge, Y. Q.; Jiang, H.; Fu, K.; Zhang, X. W. Carbon 2015, 94, 189

[84] Wang, S. Q.; Xia, L.; Yu, L.; Zhang, L.; Wang, H. H.; Lou, X. W. Adv. Energy Mater. 2016, 6, 1502217.

[85] Lei, W.; Xiao, W. P.; Li, J. D.; Li, G. R.; Wu, Z. X.; Xuan, C. J.; Luo, D.; Deng, Y. P.; Wang, D. L.; Chen, Z. W. ACS Appl. Mater. Interfaces 2017, 9, 28604.

[86] Ma, L. X.; Cao, M. X.; Zhao, C. S.; Huang, S. Z.; Ding, J. Y.; Chen, J. T.; Zhou, Y. Ceram. Int. 2021, 47, 9118.

[87] Qu, Y. H.; Zhang, Z. A.; Du, K.; Chen, W.; Lai, Y. Q.; Liu, Y. X.; Li, J. Carbon 2016, 105, 103.

[88] Yang, Y. R.; Qiu, M.; Liu, L.; Su, D.; Pi, Y. M.; Yan, G. M. Nano 2016, 11, 1650124

[89] Huo, K. F.; An, W. L.; Fu, J. J.; Gao, B.; Wang, L.; Peng, X.; Cheng, G. J.; Chu, P. K. J. Power Sources 2016, 324, 233

[90] Yang, T. Z.; Qian, T.; Wang, M. F.; Shen, X.; Xu, N.; Sun, Z.; Yan, C. Adv. Mater. 2016, 28, 539.

[91] Hao, R.; Yang, Y.; Wang, H.; Jia, B. B.; Ma, G. S.; Yu, D. D.; Guo, L.; Yang, S. H. Nano Energy 2018, 45, 220.

[92] Wang, X. L.; Li, G.; Hassan, F. M.; Li, J. D.; Fan, X. Y.; Batmaz, R.; Xiao, X. C.; Chen, Z. W. Nano Energy 2015, 15, 746.

[93] Li, W.; Zhou, M.; Li, H. M.; Wang, K. L.; Cheng, S. J.; Jiang, K. Energy Environ. Sci. 2015, 8, 2916

[94] Long, Q.; Chen, W. M.; Xiong, X. Q.; Hu, C. C.; Zou, F.; Hu, P.; Huang, Y. H. Adv. Sci. 2015, 2, 1500195.
[95] Li, Z. F.; Ma, L.; Surta, T. W.; Bommier, C.; Jian, Z. L.; Xing, Z. Y.; Stickle, W. F.; Dolgos, M.; Amine, K.; Lu, J.; Wu, T. P.; Ji, X. L. ACS Energy Lett. 2016, 1, 395.

[96] Hou, H. S.; Shao, L. D.; Zhang, Y.; Zou, G. Q.; Chen, J.; Ji, X. B.; Adv. Sci. 2017, 4, 1600243.

[97] Yang, Y.; Tang, D. M.; Zhang, C.; Zhang, Y.; Liang, Q.; Chen, S.; Weng, Q.; Zhou, M.; Xue, Y.; Liu, J. Energy Environ. Sci. 2017, 10, 979.

[98] Li, Z. F.; Bommier, C.; Chong, Z. S.; Jian, Z. L.; Surta, T. W.; Wang, X. F.; Xing, Z. Y.; Neuefeind, J. C.; Stickle, W. F.; Dolgos, M.; Greaney, P. A.; Ji, X. L. Adv. Energy Mater. 2017, 7, 1602894.

[99] Lü, H. Y.; Zhang, X. H.; Wan, F.; Liu, D. S.; Fan, C. Y.; Xu, H. M.; Wang, G.; Wu, X. L. ACS Appl. Mater. Interfaces 2017, 9, 12518.

[100] Li, Y.; Yuan, Y. F.; Bai, Y.; Liu, Y. C.; Wang, Z. H.; Li, L. M.; Wu, F.; Amine, K.; Wu, C.; Lu, J. Adv. Energy Mater. 2018, 8, 1702781.

[101] Wu, F.; Dong, R. Q.; Bai, Y.; Li, Y.; Chen, G. H.; Wang, Z. H.; Wu, C. ACS Appl. Mater. Interfaces 2018, 10, 21335.

[102] Wang, X. Y.; Hou, M. X.; Shi, Z. L.; Liu, X.; Mizota, I.; Lou, H. T.; Wang, B.; Hou, X. H. ACS Appl. Mater. Interfaces 2021, 13, 12059.

[103] Wu, L. M.; Buchholz, D.; Vaalma, C.; Giffin, G. A.; Passerini, S. ChemElectroChem 2016, 3, 292.

[104] Tao, S.; Xu, W.; Zheng, J. H.; Kong, F. J.; Cui, P. X.; Wu, D. J.; Qian, B.; Chen, S. M.; Song, L. Carbon 2021, 178, 233.

[105] Huang, S. F.; Lv, Y.; Wen, W.; Xue, T.; Jia, P.; Wang, J.; Zhang, J. J.; Zhao, Y. F. Mater. Today Energy 2021, 20, 100673.

[106] Ding, J.; Zhang, Y.; Huang, Y. D.; Wang, X. C.; Sun, Y.; Guo, Y.; Jia, D. Z.; Tang, X. C. J. Alloy. Compd. 2021, 851, 156791.

[107] Li, Y. M.; Wang, Z. G.; Li, L. L.; Peng, S. J.; Zhang, L.; Srinivasan, M.; Ramakrishnac, S. Carbon 2016, 99, 556.

[108] Wang, M.; Yang, Y.; Yang, Z. Z.; Gu, L.; Chen, Q. W.; Yu, Y. $A d v$ Sci. 2017, 4, 1600468.

[109] Gao, L. F.; Ma, J. Q.; Li, S. P.; Liu, D. J.; Xu, D. F.; Cai, J.; Chen, L. Y.; Xie, J.; Zhang, L. N. Nanoscale 2019, 11, 12626.

[110] Liu, Y.; Dai, H. D.; An, Y. K.; Fu, L. J.; An, Q. Y.; Wu, Y. P. J. Mater Chem. A 2020, 8, 14993.

[111] Yang, D.; Li, S. J.; Cheng, D. J.; Miao, L.; Zhong, W. H.; Yang, X. Q.; Li, Z. H. Energy Fuels 2021, 35, 2795.

[112] Tang, J. L.; Kye, D. K.; Pol, V. G. J. Power Sources 2018, 396, 476.

[113] Liu, M. C.; Zhang, J. Y.; Guo, S. H.; Wang, B.; Shen, Y. F.; Ai, X. P.; Yang, H. X.; Qian, J. F. ACS Appl. Mater. Interfaces 2020, 12, 17620.

[114] Wu, F.; Liu, L.; Yuan, Y. F.; Li, Y.; Bai, Y.; Li, T.; Lu, J.; Wu, C. ACS Appl. Mater. Interfaces 2018, 10, 27030.

[115] Yu, K. H.; Zhao, H. C.; Wang, X. R.; Zhang, M. H.; Dong, R. Q.; Li, Y.; Bai, Y.; Xu, H. J.; Wu, C. ACS Appl. Mater. Interfaces 2020, 12, 10544.

[116] Lu, Y. X.; Zhao, C. L.; Qi, X. G.; Qi, Y. R.; Li, H.; Huang, X. J.; Chen, L. Q.; Hu, Y. S. Adv. Energy Mater. 2018, 8, 1800108.

[117] Sun, F.; Wang, H.; Qu, Z. B.; Wang, K. F.; Wang, L. J.; Gao, J. H.; Gao, J. M.; Liu, S. Q.; Lu, Y. F. Adv. Energy Mater. 2021, 11, 2002981.

[118] Hong, K. L.; Qie, L.; Zeng, R.; Yi, Z. Q.; Zhang, W.; Wang, D.; Yin, W.; Wu, C.; Fan, Q. J.; Zhang, W. X.; Huang, Y. H. J. Mater. Chem. A 2014, 2, 12733 .

[119] Li, Y. M.; Hu, Y. S.; Titirici, M. M.; Chen, L. Q.; Huang, X. J. $A d v$ Energy Mater. 2016, 6, 1600659.

[120] Yu, Z.-E.; Lyu, Y. C.; Wang, Y. T.; Xu, S. Y.; Cheng, H. Y.; Mu, X. Y.; Chu, J. Q.; Chen, R. M.; Liu, Y.; Guo, B. K. Chem. Commun. 2020, 56, 778 .

[121] Pei, L. Y.; Yang, L. T.; Cao, H. L.; Liu, P. Z.; Zhao, M.; Xu, B. S.; Guo, J. J. Electrochim. Acta 2020, 364, 137313.

[122] Lyu, T. Y.; Lan, X. X.; Liang, L. Z.; Lin, X.; Hao, C.; Pan, Z. Y.; Tian, Z. Q.; Shen, P. K. Electrochim. Acta 2021, 365, 137356.

[123] Tang, K.; Fu, L. J.; White, R. J.; Yu, L. H.; Titirici, M. M.; Antonietti, M.; Maier, J. Adv. Energy Mater. 2012, $2,873$.

[124] Cao, Y. L.; Xiao, L. F.; Sushko, M. L.; Wang, W.; Schwenzer, B.; Xiao, J.; Nie, Z. M.; Saraf, L. V.; Yang, Z. G.; Liu, J. Nano Lett. 2012, 12, 3783

[125] Bu, L. M.; Kuai, X. X.; Zhu, W. C.; Huang, X.; Tian, K.; Lu, H.; Zhao, J. Q.; Gao, L. J. Electrochim. Acta 2020, 356, 136804.

[126] Li, W. H.; Zeng, L. C.; Yang, Z. Z.; Gu, L.; Wang, J. Q.; Liu, X. W.; Cheng, J. X.; Yu, Y. Nanoscale 2013, 6, 693

[127] Lu, P.; Sun, Y.; Xiang, H. F.; Liang, X.; Yu, Y. Adv. Energy Mater 2018, 8,1702434

[128] Wang, Z. H.; Wang, X. R.; Bai, Y.; Yang, H. Y.; Li, Y.; Guo, S. N.; Chen, G. H.; Li, Y.; Xu, H. J.; Wu, C. ACS Appl. Mater. Interfaces 
$2020,12,2481$.

[129] Prabakar, S. J. R.; Jeong, J.; Pyo, M. Electrochim. Acta 2015, 161, 23.

[130] Chen, Z.; Wang, T. H.; Zhang, M.; Cao, G. Z. Small 2017, 13, 1604045 .

[131] Ni, D.; Sun, W.; Wang, Z. H.; Bai, Y.; Lei, H. S.; Lai, X. H.; Sun, K. N. Adv. Energy Mater. 2019, 9, 1900036.

[132] Hou, H. S.; Banks, C. E.; Jing, M. J.; Zhang, Y.; Ji, X. B. Adv. Mater. 2015, 27, 7861 .

[133] Zou, G. Q.; Hou, H. S.; Foster, C. W.; Banks, C. E.; Guo, T. X.; Jiang, Y. L.; Zhang, Y.; Ji, X. B. Adv. Sci. 2018, 5, 1800241.

[134] Ren, Q. J.; Shi, Z. Q.; Yan, L.; Zhang, F. M.; Fan, L. L.; Zhang, L. J.; Lv, W. J. J. Mater. Chem. A 2020, 8, 19898.

[135] Shao, W. L.; Hu, F. Y.; Liu, S. Y.; Zhang, T. P.; Song, C.; Weng, Z. H.; Wang, J. Y.; Jian, X. G. J. Energy Chem. 2021, 54, 368.

[136] Wang, L.; Yang, G. R.; Wang, J. N.; Wang, S. L.; Peng, S. J.; Yan, W. Acta Chim. Sinica 2018, 76, 666 (in Chinese). (王玲, 杨国锐, 王嘉 楠, 王思岗, 彭生杰, 延卫, 化学学报, 2018, 76, 666.)

[137] Li, Y. M.; Xu, S. Y.; Wu, X. Y.; Yu, J. Z.; Wang, Y. S.; Hu, Y. S.; Li, H.; Chen, L. Q.; Huang, X. J. J. Mater. Chem. A 2015, 3, 71.

[138] Li, Q.; Zhu, Y. Y.; Pinyi, Z.; Yuan, C.; Chen, M. M.; Wang, C. Y. Carbon 2018, 129, 85.

[139] Xie, F.; Xu, Z.; Jensen, A. C. S.; Au, H.; Lu, Y. X.; Araullo-Peters, V.; Drew, A. J.; Hu, Y. S.; Titirici, M. M. Adv. Funct. Mater. 2019, 29, 1901072.

[140] Lu, H. Y.; Chen, X. Y.; Jia, Y. L.; Chen, H.; Wang, Y. X.; Ai, X. P.; Yang, H. X.; Cao, Y. L. Nano Energy 2019, 64, 103903.

[141] Zhu, Y. E.; Yang, L. P.; Zhou, X. L.; Li, F.; Wei, J. P.; Zhou, Z. J. Mater. Chem. A 2017, 5, 9528 .
[142] Kundu, D.; Talaie, E.; Duffort, V.; Nazar, L. F. Angew. Chem., Int. Ed. 2015, 46, 3431 .

[143] Zhang, J.; Wang, D. W.; Lv, W.; Zhang, S. W.; Liang, Q. H.; Zheng, D. Q.; Kang, F. Y.; Yang, Q. H. Energy Environ. Sci. 2017, 10, 370.

[144] Bai, P. X.; He, Y. W.; Xiong, P. Y.; Zhao, X. X.; Xu, K.; Xu, Y. H. Energy Storage Mater. 2018, 13, 274.

[145] Xiao, B. W.; Soto, F. A.; Gu, M.; Han, K. S.; Song, J. H.; Wang, H.; Engelhard, M. H.; Murugesan, V.; Mueller, K. T.; Reed, D.; Sprenkle, V. L.; Balbuena, P. B.; Li, X. L. Adv. Energy Mater. 2018, 8,1801441

[146] He, Y. W.; Bai, P. X.; Gao, S. Y.; Xu, Y. H. ACS Appl. Mater. Interfaces 2018, 10, 41380 .

[147] Hou, B. H.; Wang, Y. Y.; Ning, Q. L.; Li, W. H.; Xi, X. T.; Yang, X.; Liang, H. J.; Feng, X.; Wu, X. L. Adv. Mater. 2019, 31, 1903125.

[148] Yang, H.; Xu, R.; Yu, Y. Energy Storage Mater. 2019, 22, 105.

[149] Dong, R. Q.; Zheng, L. M.; Bai, Y.; Ni, Q.; Li, Y.; Wu, F.; Ren, H. X.; Wu, C. Adv. Mater. 2021, 2008810.

[150] He, P. L.; Qiao, Y. Battery Bimonthly 2010, 40, 161 (in Chinese). (何 鹏林, 乔月, 电池, 2010, 40, 161.)

[151] Zheng, Y. H.; Lu, Y. X.; Qi, X. G.; Wang, Y. S.; Mu, L. Q.; Li, Y. M.; Ma, Q.; Li, J.; Hu, Y. S. Energy Storage Mater. 2019, 18, 269.

[152] Mogensen, R.; Brandell, D.; Younesi, R. ACS Energy Lett. 2016, 1, 1173 .

[153] Bray, J. M.; Doswell, C. L.; Pavlovskaya, G. E.; Chen, L.; Kishore, B.; Au, H.; Alptekin, H.; Kendrick, E.; Titirici, M. M.; Meersmann, T.; Britton, M. M. Nat. Commun. 2020, 11, 2083.

(Cheng, B.) 